\title{
Continuous-cyclic variations in the $b$-value of the earthquake frequency-magnitude distribution
}

\author{
Z. H. El-Isa
}

Received: 9 July 2013/Accepted: 11 November 2013/Published online: 20 December 2013

(C) The Seismological Society of China, Institute of Geophysics, China Earthquake Administration and Springer-Verlag Berlin Heidelberg 2013

\begin{abstract}
Seismicity of the Earth $(M \geq 4.5)$ was compiled from NEIC, IRIS and ISC catalogues and used to compute $b$-value based on various time windows. It is found that continuous cyclic $b$-variations occur on both long and short time scales, the latter being of much higher value and sometimes in excess of 0.7 of the absolute $b$-value. These variations occur not only yearly or monthly, but also daily. Before the occurrence of large earthquakes, $b$-values start increasing with variable gradients that are affected by foreshocks. In some cases, the gradient is reduced to zero or to a negative value a few days before the earthquake occurrence. In general, calculated $b$-values attain maxima 1 day before large earthquakes and minima soon after their occurrence. Both linear regression and maximum likelihood methods give correlatable, but variable results. It is found that an expanding time window technique from a fixed starting point is more effective in the study of $b$-variations. The calculated $b$-variations for the whole Earth, its hemispheres, quadrants and the epicentral regions of some large earthquakes are of both local and regional character, which may indicate that in such cases, the geodynamic processes acting within a certain region have a much regional effect within the Earth. The $b$-variations have long been known to vary with a number of local and regional factors including tectonic stresses. The results reported here indicate that geotectonic stress remains the most significant factor that controls $b$-variations. It is found that for earthquakes with $M_{\mathrm{w}} \geq 7$, an increase of about 0.20 in the $b$-value implies a stress increase that will result in an earthquake with a magnitude one unit higher.
\end{abstract}

Z. H. El-Isa ( $₫)$

Geology Department, University of Jordan, Box 13929,

Amman 11942, Jordan

e-mail: elisaz@go.com.jo
Keywords Earthquake frequency-magnitude . $b$-value $\cdot$ Temporal $b$-variation $\cdot$ Spatial $b$-variation

\section{Introduction}

More than six decades ago, it was suggested by Ishimoto and Iida (1939) and Gutenberg and Richter (1944, 1954) that the magnitude distribution of earthquakes in any region follows the power law relationship of Eq. (1):

$\log N=a-b M$

where $N$ is the total number of earthquakes with magnitudes $\geq M$. The variable $a$ describes the productivity of a volume, while the slope $b$ describes the relative size distribution of earthquakes. Both parameters $a$ and $b$ are of vital importance in seismicity studies, including the estimation of seismic hazard and the calculation of recurrence time intervals of earthquakes with different magnitudes, as well as in volcano-seismicity studies including mapping subsurface magmatic chambers (Wiemer and Wyss 2002). The variable $b$ has, however, received much more attention and was subjected to many statistical, analytical and evaluation techniques within the last few decades, see El-Isa and Eaton (2013) and references therein. Different techniques have been suggested and tried to calculate the $b$-value and its uncertainty. The most used are the LeastSquare Regression and the Maximum Likelihood Methods (e.g. Aki 1965; Utsu 1965; Shi and Bolt 1982; Guttorp 1987; Wiemer and Wyss 1997). In general, there is a wide agreement among seismologists worldwide that the $b$-value displays both temporal and spatial variations; on a regional scale and for the whole Earth its value is approximately equal to 1 , but on a local scale, it shows a relatively wide range of variation (0.3-2.5) or more. Both increasing or 
decreasing $b$-values are documented before the occurrence of major earthquakes during variable periods of time that extend to many years in most cases and an immediate decrease or increase soon after their occurrence (e.g. Mogi 1962,1967; Scholz 1968; Utsu 1971; Gibowicz 1973; Wyss 1973; Fiedler 1974; Udias 1977; Robinson 1979; Smith 1981, 1986; Wang 1988; Imoto 1991; Ogata et al. 1991; Urbancic et al. 1992; Wiemer and Benoit 1996; Mori and Abercrombie 1997; Amelung and king 1997; Wiemer and Wyss 1997; Wyss and Booth 1997; Gibowicz and Lasocki 2001; Gerstenberger et al. 2001; Wiemer and Wyss 2002; Cao and Gao 2002; Del Pezzo et al. 2003; Beauval and Scotti 2004; Nuannin et al. 2005; Wyss and Stefansson 2006; Console et al. 2007; Ghosh et al. 2008; Ishibe et al. 2008; Amorese et al. 2010). Factors that contribute to spatial and temporal $b$-variations include: an increase or a decrease in effective stress, variations in crustal heterogeneity, subsurface geothermal and volcanic activities, tectonic characteristics and focal mechanisms, petrological, environmental, depth and some geophysical characteristics of rocks, quality of seismicity data and magnitude types and method of $b$-calculation and the process of application (El-Isa and Eaton 2013).

The major objectives of this study are to confirm the presence of $b$-variations, to describe their nature and to interpret the major causes of their variations. In order to eliminate much of the above mentioned factors that cause the $b$-variations, it is intended to deal with the seismicity of the Earth as a whole, its two hemispheres, four quadrants and the epicentral regions of some selected large earthquakes. To this end, seismicity data were compiled during the period January 1990 to December 2011 from three major seismicity sources, namely NEIC, IRIS and ISC. The seismicity data were subjected to detailed $b$-calculations using both the least-square regression and the maximum likelihood methods. In order to limit the effect of using different calculation methods on the $b$-variations, the leastsquare regression method was the principal technique used. Calculations were performed in different ways, using various fixed and variable time windows, including expanding and moving types. The fixed time windows had variable lengths ranging from less than a month to a month, 2 months, 1 year, 2 years, 3 years, 10 years up to 21 years. The expanding time windows had variable lengths ranging from a few days up to about two months.

\section{The seismicity data}

The seismicity of the whole Earth, its two hemispheres and four quadrants that occurred during the period January 1990 to December 2011 is utilized in this study as compiled from the catalogues of three major sources, namely the International Seismological Center (ISC), the Incorporated Research Institutions for Seismology (IRIS) and the National Earthquake Information Center (NEIC) of the United States Geological Survey. It is found that the compiled data show some differences between the three sources with regard to the total number of earthquakes, their magnitude types and occasionally their values, see Table 1. The number of events in ISC catalogues is always higher than those obtained from both NEIC and IRIS catalogues, with the latter two generally exhibiting relatively greater similarity.

For the NEIC catalogues, it is found that less than $2 \%$ of all earthquakes with $M \geq 6$ are reported with magnitudes other than the moment magnitude $\left(M_{\mathrm{w}}\right)$. For all earthquakes with magnitudes in the range $5.5 \leq M \leq 5.9$, it is found that about $95 \%$ of these are reported using $M_{\mathrm{w}}$. Only a small percentage of the earthquakes in the range $(4.5 \leq M \leq 5)$ is expressed as moment magnitudes; within this range, most events are reported with body wave magnitude $\left(m_{\mathrm{b}}\right)$. Though the seismicity data of the above mentioned three sources were subjected to $b$-calculations (see Tables 1, 3 and Fig. 1), most of the calculations presented in this paper were made utilizing the NEIC data, due to the global coverage of this catalogue and the prevalence of moment magnitudes. Preliminary $b$-calculations showed that magnitude 4.5 represents a critical threshold above which the Earth's seismicity appears to be reasonably
Table 1 The $a$ and $b$ values as calculated from the seismicity data $M \geq 4.5$ of the catalogues of NEIC, IRIS and ISC which occurred on the Earth and its two hemispheres during the period Jan. 1990-Dec. 2010

\begin{tabular}{cllll}
\hline & & NEIC & IRIS & ISC \\
\hline Eastern hemisphere & Number of earthquakes & 75,451 & 69,238 & 128,341 \\
LAT. $-90^{\circ}$ to $90^{\circ}$ & $a$ & 9.82 & 9.44 & 9.99 \\
Long. $00^{\circ}$ to $180^{\circ}$ & $b$ & 1.084 & 1.025 & 1.047 \\
Western hemisphere & Number of earthquakes & 35,846 & 30,220 & 179,001 \\
LAT. $-90^{\circ}$ to $90^{\circ}$ & $a$ & 9.64 & 9.01 & 10.11 \\
Long. $-180^{\circ}$ to $00^{\circ}$ & $b$ & 1.105 & 1.019 & 1.043 \\
Whole Earth & Number of earthquakes & 111,297 & 99,458 & 307,342 \\
& $a$ & 10.14 & 9.83 & 10.36 \\
& $b$ & 1.109 & 1.067 & 1.045 \\
\hline
\end{tabular}




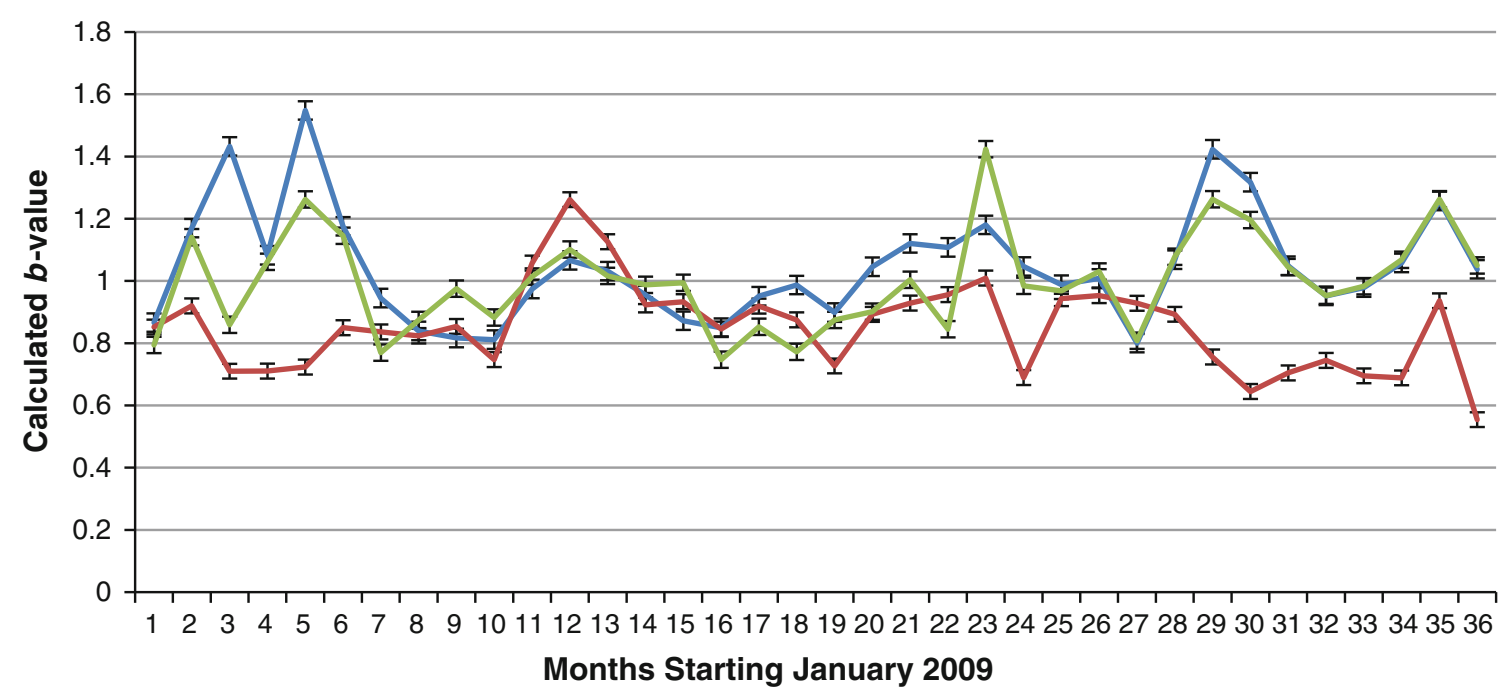

Fig. 1 The monthly $b$-values of the eastern hemisphere as calculated from the seismicity data of NEIC (blue), ISC (red) and IRIS ( $g r e e n)$ that occurred during the years 2009-2011 with magnitudes 4.5 and above. Bars represent the calculated standard errors

complete. Only slight differences were noted when using a cut-off magnitude at 5 .

Four major sets of seismicity data were used in the present analyses. These were subdivided into different categories and subjected to $b$-calculations in different manners as presented in the following sections, see Tables 1, 2, 3, 4, 5, 6 .

\section{$3 b$-Calculations}

The linear regression method is principally the main technique used in the $b$-calculations, though the maximum likelihood method is also used for comparison. The $b$-value calculations for the different study regions and sets of seismicity data were made according to the following criteria:

(1) The magnitude threshold is selected at $M=4.5$, though lower magnitudes were considered at an early stage. It is found that the seismicity data of the Earth as a whole appears to be incomplete for magnitudes $\leq 4$. A 5.0 magnitude cut-off was tried and gave only very slight $b$-differences. In order to get as large a number of earthquakes as possible in the selected time windows, it was decided to keep the cut-off at $M=4.5$. In doing so, many possible man-made explosions and induced earthquakes will be excluded.

(2) All studied seismicity data are considered as natural events and were treated without any differentiation with respect to sequences, swarms, foreshocks, mainshocks, etc.

(3) In all regression calculations of this study, the magnitude bin width was selected to be 0.5 , which insures fitting best straight lines through a minimum of five points in most $b$-calculations. Only a few cases used a lower bin width, while most calculations used more than five points.

(4) In all $b$-calculations for the different considered regions, fixed time windows were selected providing that each window included a reasonable amount of earthquake data that supply reliable results. The lengths of these windows varied from 1 month to 2 months, 3 months and 1 year, 2 years, 11 years and 21 years. Variable time window calculations were also made. For many selected large earthquakes, $b$ values were calculated from a few days up to many days before the occurrence of that particular earthquake and one day or more afterwards i.e. continuously expanding time windows. Such variable lengths of the time windows allow more detailed information on the nature and the value of the calculated $b$ variations, particularly their frequencies.

(5) To ensure robust statistics, each selected time window should contain a reasonable number of earthquakes. For all the one-month windows, the minimum earthquake numbers for all studied regions varied in the range 113-530, while the maximum numbers varied in the range 207-3058, see Tables 2, 3. Combining the datasets together increases the earthquake numbers many times in most cases, i.e. when a one-year dataset is considered, the earthquake numbers of Table 2 are increased more than ten times in some cases.

(6) All sets of seismicity data were subjected to regression analyses in different forms, including fixing the time window length in some cases and expanding it in other cases, i.e. calculating the $b$-values in continuous steps. 


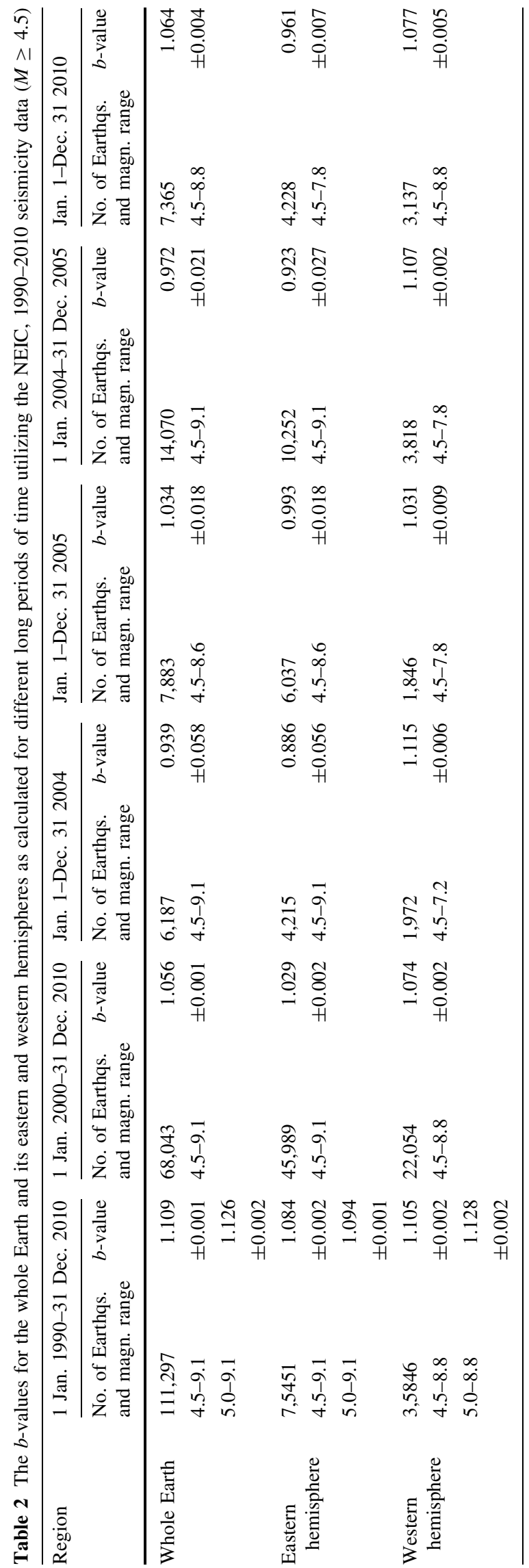

\section{Results of the $b$-calculations}

\subsection{Long time ( $\geq$ yearly) $b$-variations}

Seismicity data from the three sources were utilized to study the long time (1-2 years) $b$-variations. Results of the $b$-calculations for the data of the time period 1990-2010 are presented on Table 1. These indicate that for the whole Earth and its eastern and western hemispheres, the $a$-value varies mostly in the range 9.5-10.1 and averages at about 10.0. Variations in the $a$-value between the three sources are in the range $0.53-1.1$, while $a$-variations between the three regions are about 1.35 . The results of the three sources are generally correlatable and in agreement with many previous results (e.g. Imoto 1991; Frohlich 1993; Wiemer et al. 1998; Jackson and Kagan 1999; Jaume and Sykes 1999; Stein 2003; Mishra et al. 2007; Wech et al. 2010; El-Isa and Eaton 2013). The overall average $b$-value for the whole Earth and its two hemispheres is $1.06 \pm 0.02$. It also shows limited variations between the three seismological sources, in the range (0.06-0.08) and limited variations of about (0.09) between the three regions.

Further long time $b$-calculations were made to the NEIC seismicity data for the time intervals 2004, 2005, $2004+2005$, 2010, 2000-2010 and 1990-2010. Results are included in Table 2 and show some temporal and spatial variations. The maximum differences in $b$-values $(\Delta b)$ are found to be $0.17,0.198$ and 0.084 for the whole Earth, its eastern and western hemispheres, respectively. These results confirm that the $b$-value for the whole Earth and its two hemispheres averages around 1.0. They also confirm that the derived $b$-values show clear temporal and spatial variations, but with rather limited values. When these results are compared with each other and with the longer period of the previous section, it is noticed that the shorter the period of observation, the larger the value of the $b$-variations.

\subsection{Short time (monthly and bi-monthly) $b$-variations}

Seismicity data of the eastern hemisphere as reported in the catalogues of the three sources during the years 2009-2011 were considered in the study of short time, monthly $b$ values. The earthquake numbers varied in reasonable ranges for the three sources, Table 3. For each set of data source, $36 b$-calculations were made representing the months of the 3 years. Each calculated $b$-value is plotted on the last day of its month, see Fig. 1. The $b$-results of the three sets of data show good correlation particularly those of NEIC and IRIS. Continuous cyclic $b$-variations are observed on the three curves of Fig. 1. The $b$-differences $(\Delta b)$ as obtained from the NEIC data are $0.38,0.33$ and 
Table 3 Ranges of the monthly number of earthquakes and the calculated $b$-values for the eastern hemisphere of the Earth utilizing the seismicity data $(M \geq 4.5)$ of NEIC, IRIS \& ISC for the period 2009-2011

\begin{tabular}{llllll}
\hline & & 2009 & 2010 & 2011 & $2009-2011$ \\
\hline NEIC & Earthq. no/month & $236-479$ & $228-698$ & $342-2,220$ & \\
& $\Delta b /$ year & 0.38 & 0.33 & 0.62 & \\
& $\Delta b / 3$ year & & & $321-2,253$ & \\
\multirow{2}{*}{ IRIS } & Earthq. no/month & $183-438$ & $232-767$ & 0.46 & \\
& $\Delta b /$ year & 0.49 & 0.68 & & 0.68 \\
& $\Delta b / 3$ year & & & $530-3,058$ & \\
ISC & Earthq. no/month & $437-840$ & $524-1,145$ & 0.40 & 0.70 \\
& $\Delta b /$ year & 0.55 & 0.28 & & \\
\hline
\end{tabular}

decrease is observed to have occurred during the last 4 months of 2004 to about 0.675 . Further $b$-variations are observed to have taken place during the year 2005 when the maximum observed value (1.43) occurred in September.

Some 22 earthquakes including all with magnitudes $\geq 7.0$, the largest two Sumatra (9.1 of 26 December 2004 and 8.6 of 28 March 2005) and some selected M6.0-M6.9 earthquakes are also marked on the graph according to their times of occurrence. Further $b$-calculations were made to $(22 \times 2)$ time windows that include the seismicity data of each of these 22 earthquakes on its own; one window ends a day before and the other on the day of occurrence of each earthquake. The window lengths varied mostly in the range 25-35 days. Results are plotted in red on Fig. 3. These results show that for all 22 earthquakes, each $b$-value achieved a maximum one day before and a minimum soon after the occurrence of the concerned earthquake and its immediate aftershocks. Soon after that, the $b$-values continue to change either positively, e.g. the two largest Sumatra earthquakes, or negatively as seen on some cases of Fig. 3, e.g. the M7.4 earthquake of 6 September 2004 and the $M 7.2$ earthquake of July 2005 . The $\Delta b$ values, i.e. the differences between the maximum and minimum $b$ values of each earthquake, vary in the range $0.05-0.61$. The largest $\Delta b$ is associated with the 7.4 earthquake of September 2004, followed by the 7.6 earthquake of October 2005. In both cases the background $b$-values were relatively high. In the case of the largest Sumatra earthquake (M9.1), the calculated $\Delta b$ is only about 0.38 , but it occurred in December 2004 when the background $b$ was in one of its lowest values, see Fig. 3. The same is observed for the second largest Sumatra earthquake $(\Delta b=0.34)$. It should also be mentioned that all calculated $b$-values show slight changes with the lengths of the time windows, but the maxima 1 day before and the minima after their occurrences are always observed irrespective of the lengths of the time windows.

The NEIC earthquakes that occurred in quadrant 1 during the years 2004-2005 were also subjected to $b$-calculations using fixed windows of 2 months. The first 


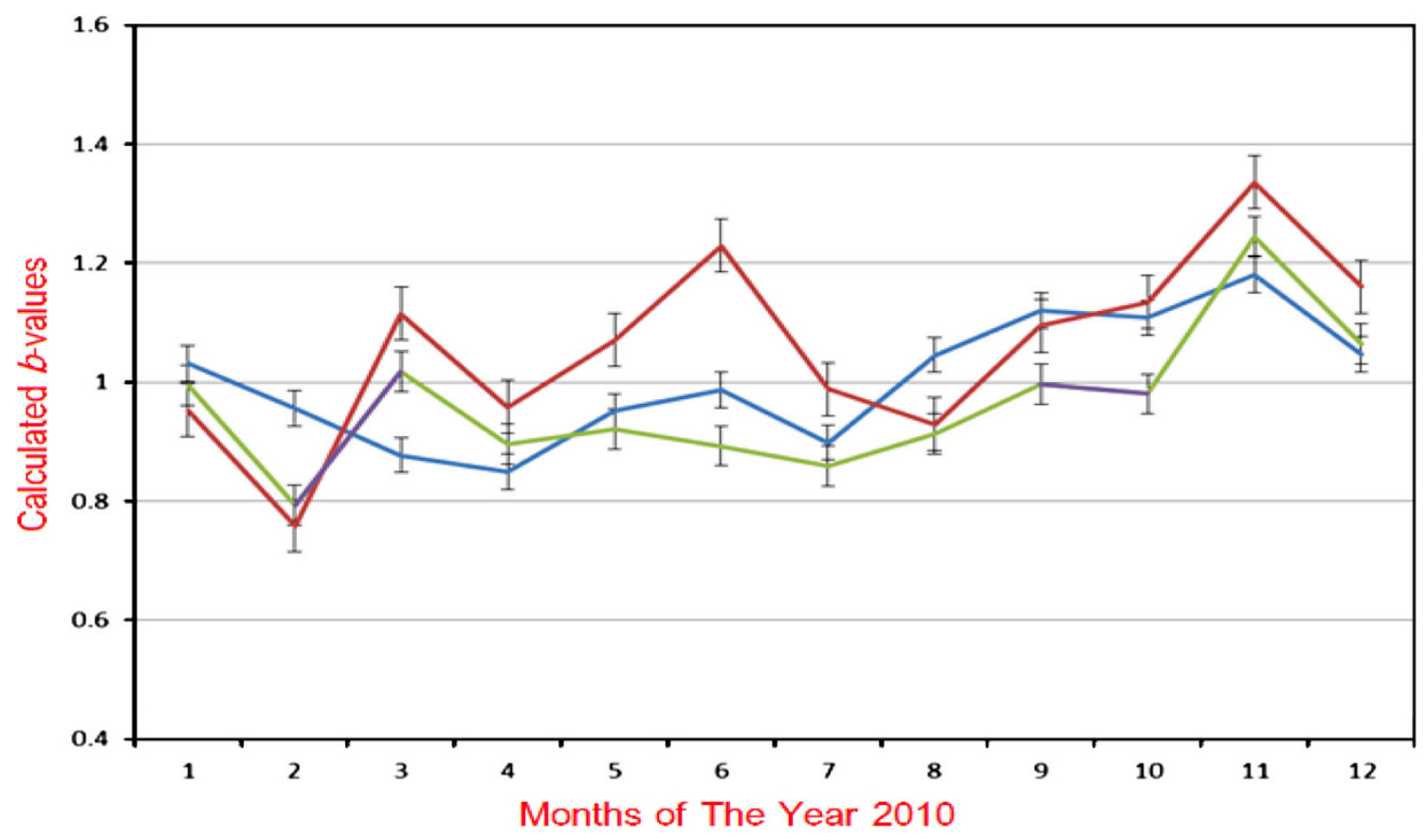

Fig. 2 Calculated $b$-values from NEIC seismicity data $(M \geq 4.5)$ for the whole Earth (green) and its eastern (blue) and western (red) hemispheres during the months of the year 2010. Standard errors are represented by the vertical bars

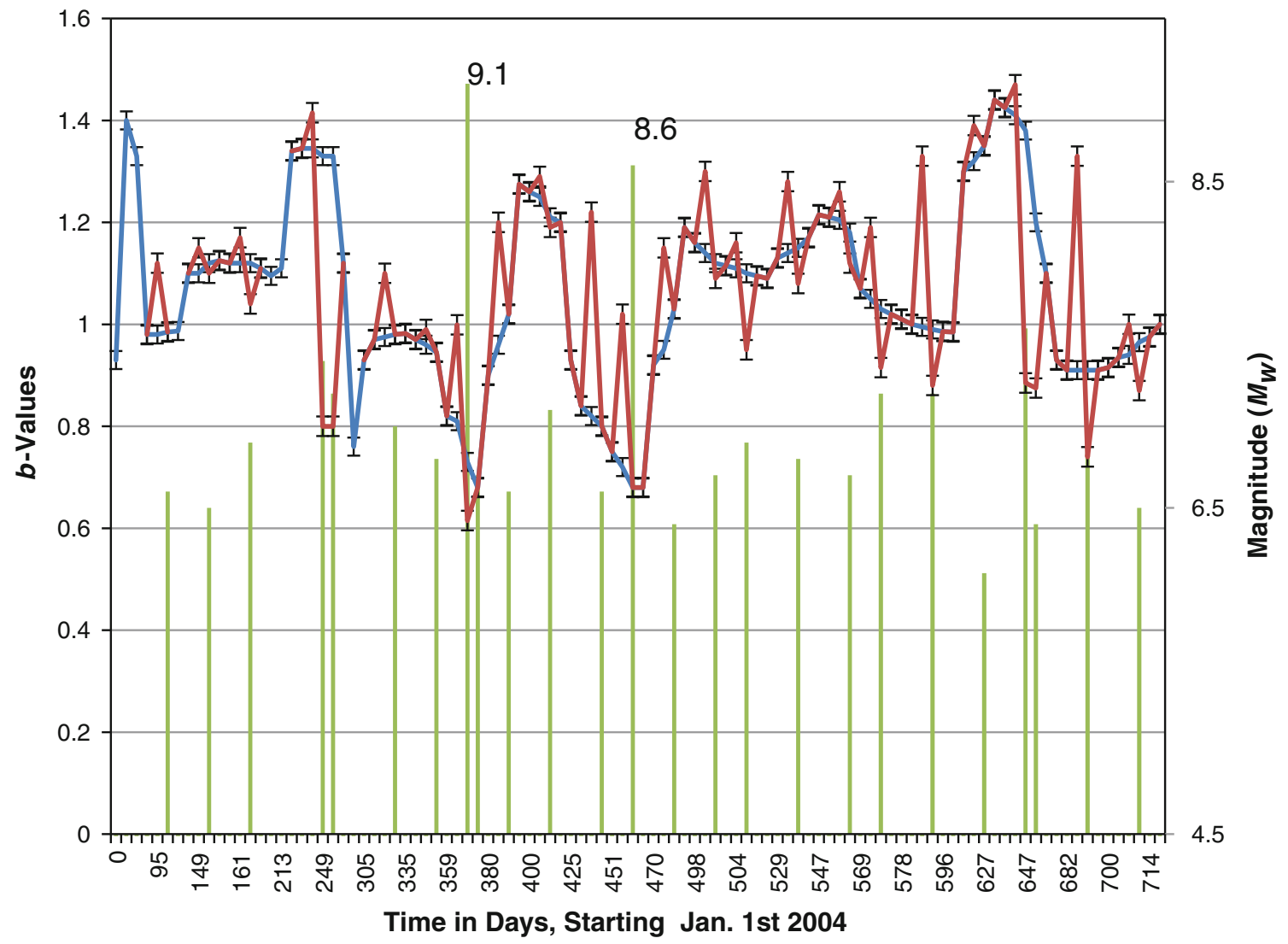

Fig. 3 The monthly $b$-values as calculated from the seismicity data of quadrant 1 that occurred during the 2 years 2004-2005 (Blue line), and the calculated $b$-values one day before and soon after the occurrence of the 22 selected earthquakes (in red) 


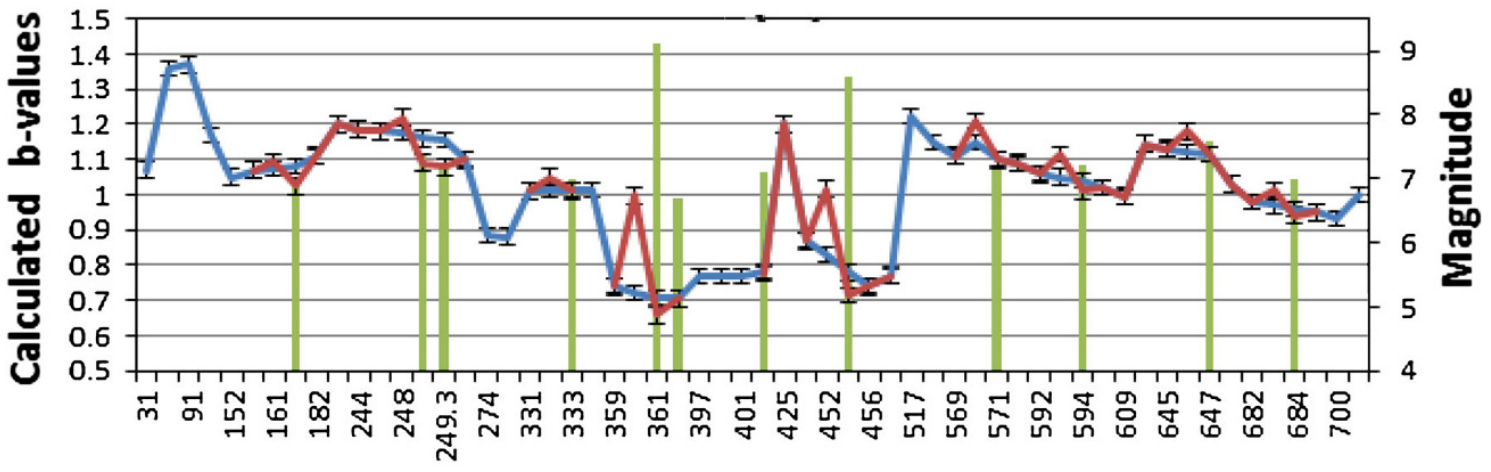

Days starting January 1, 2004

Fig. 4 The $b$-values as calculated from the 2004 and 2005 NEIC seismicity data of Quadrant 1 utilizing 2 months time windows. The red lines show the calculated $b$-values for some selected large earthquakes utilizing time windows that end 1 day before and after their occurrence

calculated $b$ of the two months case utilized the seismicity data of December 2003 in addition to that of January 2004. The result is plotted in Fig. 4 to represent the $b$-value as on 31 st January 2004. The next $b$-value is calculated from the seismicity data of both January and February and is plotted on 29 February 2004 and so on. The same window is moved month-by-month thereafter. The final results are presented by the blue lines in Fig. 4, where the calculated $b$-value of each window is plotted on its last day. These show that the $b$-values vary continuously with time in the range 0.71-1.37. A general $b$-decrease is observed during the period April-December 2004 and a general increase is observed thereafter up to the end of June 2005, when it starts decreasing again. Further $b$-calculations were made to the seismicity data 1 day before and after the occurrence of ten selected earthquakes. Results are plotted (in red) on Fig. 4. For both windows, nine of these earthquakes showed the $b$-values attain local maxima one day before each earthquake and local minima soon thereafter. The $\Delta b$ values varied in the range (0.05-0.34), the highest being that value associated with the M9.1 earthquake of 26 December 2004. The second largest $(\Delta b=0.3)$ is that associated with the second largest Sumatra M8.6 earthquake of 28 March 2005. The only earthquake whose $b$ value increased after occurrence is a $M 7.1$ earthquake that occurred on 5 February 2005. The $b$ increased from 0.773 to 0.7756 , i.e. only 0.0026 , i.e. small enough to be within the range of accuracy. Furthermore, this earthquake occurred during the period when the $b$-value was showing a general increase as mentioned above, see Fig. 4.

\subsection{Short time (daily) $b$-variations}

To study the short time daily $b$-variations, the largest three earthquakes of the year 2010 were selected for further analyses. These include the $M_{\mathrm{w}} 8.8$ Chile earthquake of
February 27 , with its epicentre at $36.12^{\circ} \mathrm{S}, 72.9^{\circ} \mathrm{W}$ in Quadrant (3) of the Earth; a $M_{\mathrm{w}} 7.8$ Sumatra earthquake that occurred on April 6, with its epicentre at $2.38^{\circ} \mathrm{N}, 97.05^{\circ} \mathrm{E}$ (Quadrant 1); and a $M_{\mathrm{w}} 7.8$ earthquake that occurred on October 25 with an epicentre located at $3.49^{\circ} \mathrm{S}, 100.08^{\circ} \mathrm{E}$ (Quadrant 2). Calculations were made to the $b$-values from the NEIC seismicity data of the whole Earth, its two hemispheres and four quadrants separately. For the Chile earthquake, the $b$-value was calculated twice, the first used the seismicity data for the period February 1 to February 26, while the second used one more day to the first set, i.e. February 1-February 27. For the Sumatra earthquake, the two $b$-calculations utilized the data of the periods March 1April 6 and 7. For the third earthquake the two time periods started October 1-October 24 and 25. Results are summarized in Table 4. These examples clearly indicate that for each of these earthquakes, the $b$-value of its quadrant increased to a maximum on the previous day of its occurrence. Immediately after the earthquake, the $b$-value dropped to a minimum. The total drop in the $b$-value of quadrant 3 where the Chile earthquake occurred is 0.350 . Considering the two hemispheres of the Earth, the $b$-value of the concerned hemisphere also increased to a maximum before the earthquake and dropped to a minimum thereafter. Before the Chile earthquake, the $b$-value of the western hemisphere increased to 1.146 . On its occurrence, it dropped down to 0.73, a difference of 0.416 , see Table 4 . The same phenomenon is observed for the whole Earth whose $b$-value decreased in the Chile earthquake case from 1.063 to 0.769 , i.e. a difference of 0.294 . In the Sumatra case, the $b$-value of the whole Earth dropped by 0.122 from 1.133 to 1.011 . In the third case, it dropped down by 0.351 from 1.286 to 0.935 , see Table 4 .

Further $b$-calculations were made to the seismicity data of the Chile earthquake utilizing the expanding and the moving time window techniques. In the first, $b$-values were 


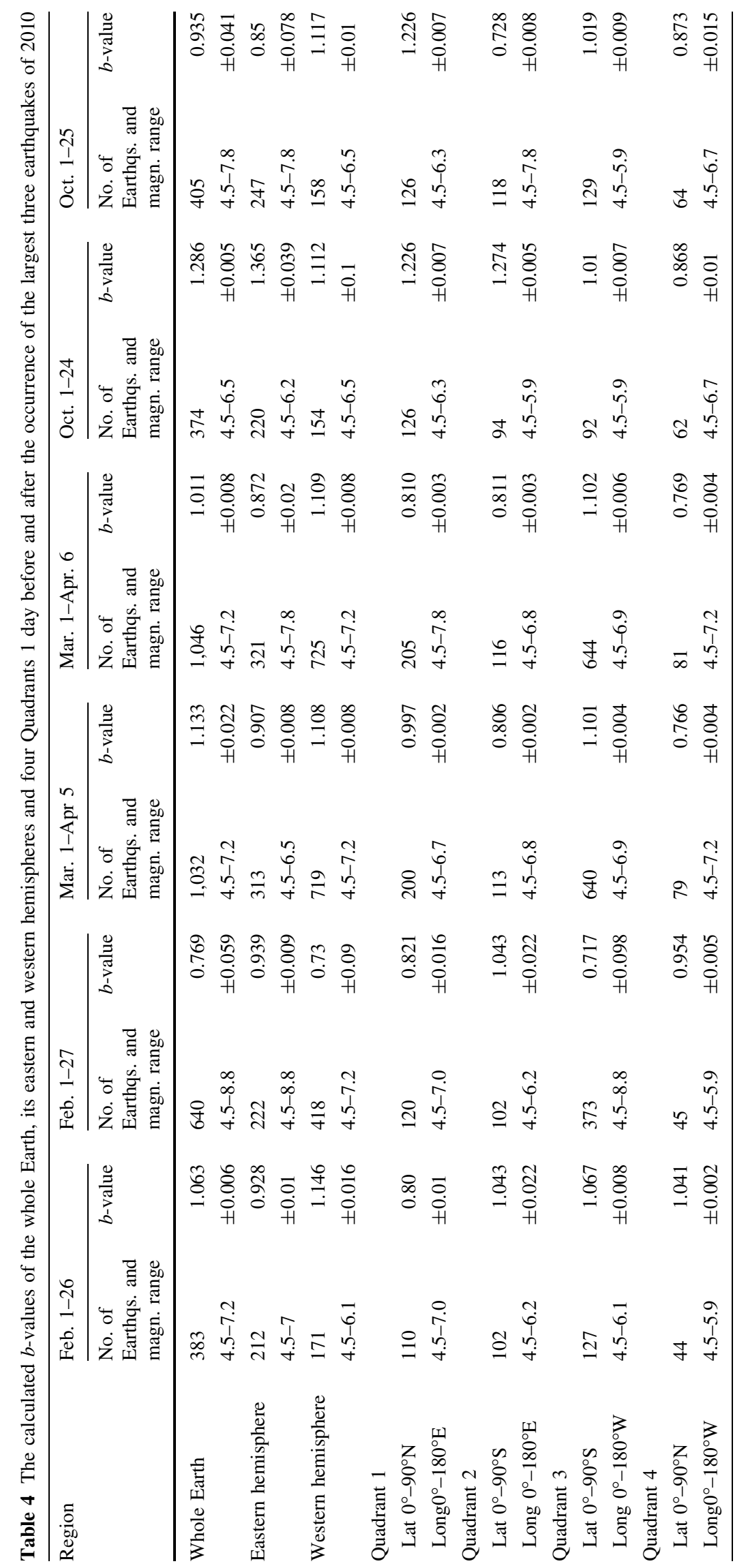



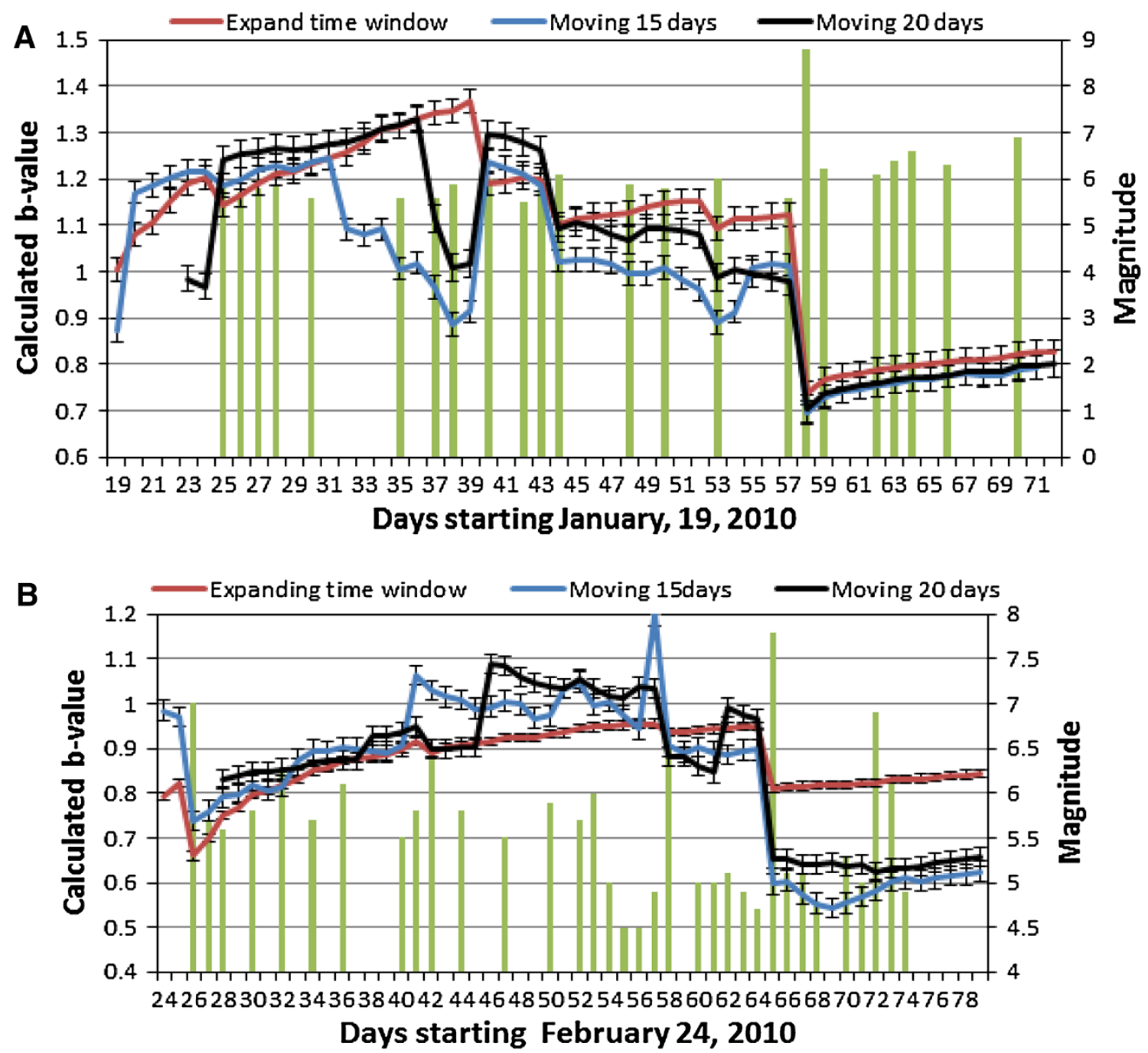

Fig. 5 Calculated $b$-values for a Quadrant 3 of the Earth during a period of 39 days before and 14 days after the Chile, 2010 earthquake $\left(M_{\mathrm{w}}=8.8\right)$ and $\mathbf{b}$ Quadrant 1 of the Earth for a period of 41 days before and 14 days after the largest 2010 Sumatra earthquake $\left(M_{\mathrm{w}}=7.8\right)$. Large earthquakes are marked with their times and magnitudes. Bars represent the calculated standard errors

calculated 54 times utilizing the seismicity data of the western half of the Earth and 54 time windows that expanded one day at a time. The first time window includes 8 days representing the period January $12-19$, the second window includes the same 8 days plus one, i.e. January 12-20 and the last includes 61 days that cover the period from January 12 to March 13. Results are plotted in red colour on Fig. 5a, which also shows the times and magnitudes of the earthquakes that occurred during the same period with magnitudes $M_{\mathrm{w}} \geq 5.6$. For those days which include two or more earthquakes, only the largest magnitude is marked. In the second, two time windows were selected with 15 and 20 days. The $b$-values were calculated from the seismicity data of the first window, which includes the period January 5-19, 2010 whose result is plotted on January 19. The window is moved 1 day and its result is plotted on January 20, and so on to many days after the 8.8 earthquake. The same process is repeated with a 20 days window. Results are presented on Fig. 5a in blue and black colours, respectively.

The expanding-window results (red colour) show that the $b$-value has varied in the range $1.366-0.739$ during the 54 days, spanning a range of 0.627 . An overall increase in the $b$-value is observed during the 39 days before the occurrence of the earthquake. Between January 19 and 24, the $b$-value increased from 1.005 to 1.203 at an average gradient of about $0.04 /$ day. Two earthquakes that occurred on January 25 with magnitudes 5.9 and 5.6 are associated with a $b$-value drop to 1.143 . A gradual increase is observed thereafter, which continued to February 8 with a gradient of about $0.016 /$ day. During this period, seven earthquakes occurred within this quadrant with magnitudes 5.6-5.9. Each of these is seen on Fig. 5a to reduce the $b$ gradient on its day of occurrence. On February 9, a 6.0 
magnitude earthquake resulted in lowering the $b$-value to 1.191, beyond which it started increasing again at a lower gradient of 0.003/day. On February 13, another $6.1 \mathrm{mag}-$ nitude earthquake resulted in lowering its value to 1.102 . During the following 8 days, the $b$-value increased continuously at an average gradient of about $0.006 /$ day. On February 22, three earthquakes $(M=6.0,5.7$ and 5.6) resulted in $b$ - reduction to 1.093 . During the following 4 days, the $b$-value increased to 1.124 at an average gradient of $0.008 /$ day. It should be noted that none of the above mentioned earthquakes is located within the epicentral region of the February 27 Chile earthquake. On the occurrence of this major earthquake and its immediate aftershocks, the $b$-value of quadrant 3 was lowered down to 0.739. During the following 14 days, its value is observed to increase continuously, but at variable gradients, being largest within the first 1-2 days. All marked earthquakes of these 14 days period occurred within the epicentral region of the Chile earthquake. Most of these are clearly observed to have resulted in lowering the $b$-gradient, see Fig. 5a.

The moving-window results (blue and black curves) also show large variations. Differences between the highest and lowest $b$-values are 0.55 and 0.626 for the 15 and 20 day windows, respectively. Both curves show a gradual $b$ increase during the first 12-17 days. The sharp jump on both curves on January 20 and 25 is simply caused by dropping off the 6.8 earthquake of January 5 from the windows. Around February 8-9, the $b$-value of both windows and that of the expanding method show maximum values. Beyond that and up to February 26, the values of the three curves are reduced due to the occurrence of the marked earthquakes. On the occurrence of the major 8.8 Chile earthquake, the $b$-value of both windows dropped down to about 0.7 . During the following 2 weeks, the $b$ value of both windows started increasing at the same gradient, which is the highest during the first 2 days.

Similar calculations were made for the Sumatra earthquake of April 6, for a period extending from 41 days before its occurrence to 14 days after. The first $b$-calculation was made for the seismicity data of Quadrant (1) of the Earth for the period February 17-24, including some 36 earthquakes ( $4.5 \leq M \leq 6.9$ ). The second was for the same period plus 1 day and included 40 earthquakes. The last was for a 70-day time window that expanded between February 17 and April 20, 2010. This window included 352 earthquakes $(4.5 \leq M \leq 7.8)$. Results show that the $b$ value varies in the range $0.66-0.955$ as indicated by the red curve in Fig. 5b. On February 25, a M7 earthquake and three others of magnitude 5.5-5.7 resulted in lowering the $b$-value of Quadrant (1) from 0.821 to 0.66 . Within the following 4 days, it increased to 0.797 with a gradient $0.034 /$ day. Within the following 11 days it increased gradually at a lower gradient $(0.011 /$ day $)$ to become 0.916 on March 13. It then dropped down to 0.892 the following day, which correlates with the occurrence of a $M_{\mathrm{w}} 6.5$ earthquake. Within the following 10 days, the $b$-value continued to increase at a variable gradient with an average $0.005 /$ day. Within the following 5 days it continued increasing at a lower gradient of 0.002/day. On 30 March 2010, a M6.7 earthquake resulted in lowering its value from 0.955 to 0.936 . Within the following 6 days, it continued its increase to 0.951 with a gradient $0.0024 /$ day. On the occurrence of the M7.8 Sumatra earthquake of April 6 and its immediate aftershocks, the $b$-value dropped down to 0.81 . During the following 14 days, the $b$-value of Quadrant (1) began to increase at an average gradient of $0.0023 /$ day. The occurrence of three earthquakes $\left(M_{\mathrm{w}} 6.9,6.1\right.$ and 5.6) during this period is seen in Fig. $5 b$ to have affected this gradient.

Similar calculations were made using same seismicity data with moving windows of 15 and 20 days. Results are plotted on Fig. 5b in blue and black colours and show variations in the ranges $0.543-1.2$ and $0.642-1.09$. Both curves clearly show that the $b$-value increases gradually from February 26, when a $M 7$ earthquake occurred, to March 30 when a M6.7 foreshock occurred. Two sharp jumps are observed on March 13 and 18. These are caused by the removal of the magnitude 7 earthquake of February 26 from the window of calculation. Two similar jumps are also observed on March 29 and April 3. These are caused by the removal of the M6.5 earthquake of March 14. The M6.7 foreshock and a few more foreshocks with magnitudes less than 5 as well, as a few others that occurred elsewhere in quadrant 1 , result in lowering of the $b$-value during the period March 29-April 5 to 0.898 and 0.966 for both windows. Upon the occurrence of the M7.8 Sumatra earthquake of April 6, the $b$-values are reduced for both windows to 0.596 and 0.651 , respectively. Beyond that date, the $b$ started increasing again with relatively low gradients. Large aftershocks are seen to have affected its increase.

The $b$-results as obtained from the 2010 seismicity data of the whole Earth show that in the three largest earthquake cases, the $b$-values of the concerned quadrants, hemispheres and whole Earth have gradually increased to maxima immediately before each earthquake and dropped to minima soon thereafter. Calculations of the $b$-values for the other three quadrants and hemisphere indicate that it mostly increased very slightly or remained unchanged. The October 25 earthquake that occurred in quadrant 2 resulted in a reduction in $b$-value by 0.546 , while it increased by the amounts 0.009 in quadrant $1,0.009$ in quadrant 3 and 0.006 in quadrant 4 . In the case of the Chile earthquake, the $b$ value of quadrant 3 dropped by the amount 0.385 . It also dropped 0.087 in quadrant 4 , remained unchanged in quadrant 2 and increased 0.021 in quadrant 1 . In general, 

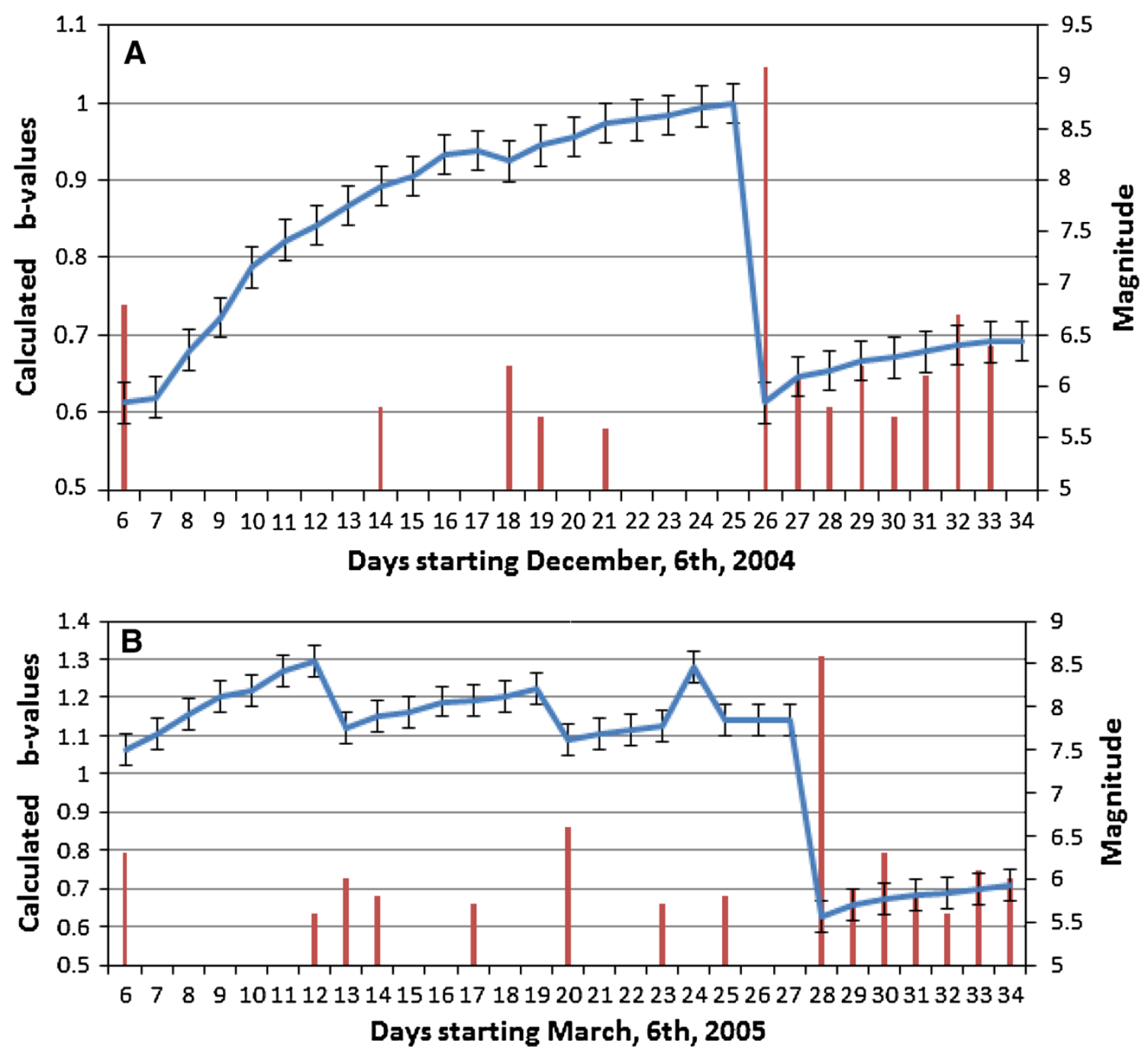

Fig. 6 Calculated $b$-values for quadrant 1 during a period of 29 days before and after the occurrence of a The largest Sumatra earthquake of 26 December 2004 and b The second largest Sumatra earthquake of 28 March 2005

the $b$-variations of the other three quadrants appear to be incoherent and small, mostly within the accuracy of the $b$ calculations. Contrary to this, the $b$-variations of the concerned quadrants, hemispheres and the whole Earth remain systematic and of relatively large values approaching in some cases more than $50 \%-60 \%$ of total $b$.

The two largest Sumatra earthquakes of 26 December 2004 (M9.1) and 28 March 2005 (M8.6) were selected for further $b$-calculations to quadrant 1 of the Earth, utilizing expanding time windows. In the case of the M9.1 earthquake, $29 b$-values were calculated utilizing the seismicity data of 29 time windows that have the same starting point, December 1. The first window ends on December 6, the second on December 7, thus adding 1 day to each successive window, with the last window ending on 3 January 2005. Final results are presented on Fig. 6a. On December 6, a $M 6.8$ earthquake resulted in lowering the $b$-value to about 0.612 , beyond which it started increasing at a gradient of about $0.05 /$ day up to December 11 . At this time a few earthquakes occurred with $M \leq 5.5$ which resulted in lowering the gradient to about $0.02 /$ day. On December 18 , a M6.2 earthquake occurred and resulted in lowering the $b$ value from 0.939 to 0.925 and a reduction in the gradient to about $0.011 /$ day. On December 25, the $b$-value increased to a maximum of 0.999 . Upon the occurrence of the M9.1 earthquake and its immediate aftershocks, the $b$-value was reduced to 0.612, see Fig. 6a. Soon after December 26, the $b$-value started increasing again at variable gradients that appear to correlate well with large aftershocks. These results demonstrate quite clearly how the $b$-value of Quadrant 1 of the Earth increases gradually for some time before major earthquakes. Before each large earthquake it attains a maximum and it is reduced to a minimum subsequent to occurrence of the earthquake. Other smaller, yet relatively significant earthquakes, also reduce the $b$-values or at least reduce their rate of increase. 
Similar analyses were carried out on the seismicity data of quadrant 1 for the period March 1 to April 3, 2005 in order to study the $b$-variations before and after the occurrence of the second largest Sumatra earthquake of 28 March 2005. Final results are presented on Fig. 6b which also displays the mainshock, eight possible foreshocks and six aftershocks. The $b$-value shows a general increase up to March 27 with variable gradients, 0.039/ day for the first week, $0.017 /$ day during the second week, $0.047 /$ day during the third week and a smaller gradient of only $0.002 /$ day during the last two days before the earthquake. On March 27, the $b$-value reached a maximum of 1.142 and subsequently dropped to 0.628 on March 28, i.e. $\Delta b=0.514$. During the following 6 days, the $b$-values started increasing again at a rate of $0.014 /$ day. Similar to the previous earthquake, the $b$-values and their gradients are reduced with foreshock and aftershock occurrences, see Fig. $6 \mathrm{~b}$.

\section{$4.4 b$-Values of the largest earthquakes of the earth during the period 1990-2010}

Search in the NEIC bulletins showed that during the period 1 January 1990-31 December 2010 some 77 earthquakes occurred in the eastern hemisphere of the Earth with magnitude $\geq 7.5$ and only 27 earthquakes occurred in its western hemisphere within the same period and magnitude range. All these earthquakes and 10 more that occurred in the western half with magnitudes $7.3 \leq M_{\mathrm{w}} \leq 7.4$ were subjected to $b$-calculations utilizing two time windows that start at fixed date and end one day before the earthquakes for one window and a day after for the second. The time periods of most windows varied in the range 35-45 days. In these $b$-calculations, both the least-square regression and the maximum likelihood methods were used. Results are included in Tables 5, 6. The total number of earthquakes used in these calculations varied in the range 200-565. Only $9 b$-values were calculated using less than 100 earthquakes, see Tables 5, 6. These show that $b$-values as calculated for each earthquake are not equal from both methods. There is always a difference that reaches, in a few cases, a value close to 0.6 or slightly more, but differences vary for most cases in the range 0.1-0.4. Excluding only one earthquake (number 30 of Table 5), all calculated $b$ values from the regression method show a maximum one day before and a minimum soon after the occurrence of each earthquake. This earthquake was preceded by five large earthquakes with magnitudes in the range 6.5-7.2 and followed by other three with magnitudes in the range 6.5-7.3. The maximum likelihood method also shows the same maxima and minima for all earthquakes of both tables excluding only six cases, numbers 28, 36, 47 and 64 of Table 5, and numbers 5 and 20 of Table 6 .

\section{Discussion}

The $b$-value is a quantitative measure of the earthquake size distribution within a certain period of time in any region. The occurrence of small magnitude earthquakes increases its value, while it decreases with the occurrence of only one large magnitude earthquake or more. As the occurrence of earthquakes is unpredictable in both time and space, the $b$-value should, therefore, vary accordingly. The detailed calculations on the seismicity data of sections I, II, III and IV including both long time and short time sets of seismicity data clearly indicate that the $b$-value appears to vary continuously with time in a cyclic manner. Long time variations are of relatively low amplitudes; the longer the period, the lower the amplitude. Short time sets of data (1 or 2 months or shorter) show that the $b$-variations of the whole Earth, its two hemispheres and four quadrants as well as the epicentral regions of some selected large earthquakes attain $b$-variations with amplitudes as high as 0.6-0.7 of its absolute value. Such variations are continuous and cyclic and occur not only on a yearly or monthly basis, but also daily for many days before and after large earthquakes.

These calculations also confirm that the $b$-variations are also affected by the selected calculating technique and how it is applied. Differences are observed between the results of both regression and maximum likelihood methods. Tables 5, 6 confirm this and show that in some cases, the difference between the calculated $b$ for the same dataset is as high as 0.6 , or slightly more, though in most cases the differences are less than 0.3. Both the regression and the maximum likelihood methods are sensitive to small numbers of earthquakes in the time window. This is particularly true for the maximum likelihood method which may result in highly anomalous results. Nevertheless, the results of Tables 5, 6 clearly show that: (i) a reasonable correlation is observed between the results of both methods, as long as the numbers of earthquakes in the analyzed windows are large, (ii) considering the results of each method on its own, $b$-variations before and after each of the tabulated 111 earthquakes are clearly documented. The $b$-values of 110 , i.e. $99 \%$ of all earthquakes as calculated from the regression method show maxima 1 day before and minima soon after their occurrence. The only case which gave a contrary result is a 7.5 magnitude earthquake which was followed by three large aftershocks with magnitudes in the range 6.5-7.3. Only six earthquakes gave contrary results from the maximum likelihood method, i.e. more than $94 \%$ of these earthquakes show $b$-maxima and $b$-minima before and after their occurrence, (iii) the calculated $b$-value is also affected, albeit slightly, by the length of the time window. This is evident for the $b$-values of the Chile 2010, Sumatra 2004, 2005 and 2010 as presented on Figs. 3, 4 
Table 5 The $b$-values for all earthquakes that occurred within the eastern hemisphere during the period 1990-2010 with magnitudes $\geq 7.5$ as calculated 1 day before and after their occurrences, utilizing both the least-square regression and the maximum likelihood methods. The total number of earthquakes used in each $b$-calculation and their magnitude ranges are also tabulated. Most numbers varied in the range 222-565. Only two earthquakes had $N=100$. Standard deviations for all $b$-calculations varied mostly in the range \pm 0.004 to \pm 0.098

\begin{tabular}{|c|c|c|c|c|c|c|c|c|c|c|c|}
\hline \multirow[t]{2}{*}{ Number } & \multirow[t]{2}{*}{ Date } & \multirow[t]{2}{*}{$M_{\mathrm{w}}$} & \multirow[t]{2}{*}{ Quadrant } & \multicolumn{4}{|c|}{$\begin{array}{l}\text { Number of earthquakes }(N) \text {, magnitude range } \\
\text { (MR) and the } b \text {-value one day before each } \\
\text { earthquake as calculated through }\end{array}$} & \multicolumn{4}{|c|}{$\begin{array}{l}\text { Number of earthquakes, magnitude range (MR) and } \\
\text { the } b \text {-value on the same day after each earthquake as } \\
\text { calculated through }\end{array}$} \\
\hline & & & & $N$ & MR & $\begin{array}{l}\text { Regression } \\
\text { method }\end{array}$ & $\begin{array}{l}\text { Max likelihood } \\
\text { method }\end{array}$ & $N$ & MR & Regression method & $\begin{array}{l}\text { Max likelihood } \\
\text { method }\end{array}$ \\
\hline 1 & 3.3 .1990 & 7.6 & 2 & 257 & $4.5-6.9$ & 0.9890 & 1.1761 & 276 & $4.5-7.6$ & 0.8523 & 1.1140 \\
\hline 2 & 18.4 .1990 & 7.6 & 1 & 464 & $4.5-6.7$ & 0.9001 & 1.0188 & 506 & $4.5-7.6$ & 0.8309 & 0.9780 \\
\hline 3 & 16.7.1990 & 7.7 & 1 & 355 & $4.5-7.4$ & 0.9113 & 1.0509 & 429 & $4.5-7.7$ & 0.8677 & 1.0316 \\
\hline 4 & 30.12 .1990 & 7.5 & 2 & 244 & $4.5-6.7$ & 1.2018 & 0.8973 & 261 & $4.5-7.5$ & 0.9007 & 0.8862 \\
\hline 5 & 20.6 .1991 & 7.5 & 1 & 208 & $4.5-6.3$ & 1.2689 & 1.2425 & 222 & $4.5-7.5$ & 0.8526 & 1.1977 \\
\hline 6 & 22.12 .1991 & 7.6 & 1 & 213 & $4.5-6.8$ & 0.9335 & 0.9696 & 245 & $4.5-7.6$ & 0.8537 & 0.9509 \\
\hline 7 & 12.12 .1992 & 7.8 & 2 & 293 & $4.5-6.4$ & 1.0752 & 1.0586 & 328 & $4.5-7.8$ & 0.9522 & 1.0160 \\
\hline 8 & 15.1 .1993 & 7.8 & 1 & 377 & $4.5-6.8$ & 0.9191 & 0.9828 & 383 & $4.5-7.8$ & 0.8209 & 0.9631 \\
\hline 9 & 12.7.1993 & 7.7 & 1 & 290 & $4.5-7.5$ & 0.8874 & 1.0460 & 325 & $4.5-7.7$ & 0.7943 & 1.0125 \\
\hline 10 & 8.8.1993 & 7.8 & 1 & 308 & $4.5-7.7$ & 0.8891 & 1.0761 & 331 & $4.5-7.8$ & 0.7876 & 1.0656 \\
\hline 11 & 8.6.1993 & 7.5 & 1 & 269 & $4.5-7.0$ & 0.9944 & 1.0421 & 277 & $4.5-7.5$ & 0.8348 & 1.0195 \\
\hline 12 & 2.6 .1994 & 7.8 & 2 & 273 & $4.5-6.6$ & 0.9271 & 1.0328 & 292 & $4.5-7.8$ & 0.8786 & 1.0293 \\
\hline 13 & 4.10 .1994 & 8.3 & 1 & 268 & $4.5-6.8$ & 0.9980 & 1.0639 & 369 & $4.5-8.3$ & 0.8141 & 0.9388 \\
\hline 14 & 28.12.1994 & 7.8 & 1 & 172 & $4.5-6.5$ & 1.1653 & 1.0332 & 209 & $4.5-7.8$ & 0.8548 & 0.8960 \\
\hline 15 & 16.5.1995 & 7.7 & 2 & 192 & $4.5-7.1$ & 0.8860 & 1.2596 & 229 & $4.5-7.7$ & 0.7796 & 1.1742 \\
\hline 16 & 16.8 .1995 & 7.7 & 2 & 58 & $4.5-6.7$ & 0.8860 & 1.4151 & 87 & $4.5-7.7$ & 0.6356 & 0.8849 \\
\hline 17 & 3.12 .1995 & 7.9 & 1 & 249 & $4.5-7.2$ & 0.9289 & 1.0934 & 336 & $4.5-7.9$ & 0.8582 & 0.9906 \\
\hline 18 & 1.1 .1996 & 7.9 & 1 & 431 & $4.5-6.3$ & 0.8949 & 1.0635 & 451 & $4.5-7.9$ & 0.8064 & 1.0391 \\
\hline 19 & 17.2.1996 & 8.2 & 2 & 139 & $4.5-7.2$ & 0.8057 & 1.3180 & 223 & $4.5-8.2$ & 0.6834 & 1.2182 \\
\hline 20 & 17.6.1996 & 7.9 & 2 & 107 & $4.5-7.1$ & 0.7700 & 1.1279 & 115 & $4.5-7.9$ & 0.6640 & 1.0604 \\
\hline 21 & 21.4.1997 & 7.7 & 2 & 175 & $4.5-6.5$ & 1.1285 & 1.4587 & 224 & $4.5-7.7$ & 0.8416 & 1.2115 \\
\hline 22 & 8.11 .1997 & 7.5 & 1 & 295 & $4.5-6.5$ & 1.2096 & 1.2954 & 310 & $4.5-7.5$ & 0.8910 & 1.2859 \\
\hline 23 & 5.12 .1997 & 7.8 & 2 & 321 & $4.5-7.5$ & 0.7944 & 1.3667 & 441 & $4.5-7.8$ & 0.7581 & 1.3412 \\
\hline 24 & 4.1.1998 & 7.8 & 2 & 492 & $4.5-7.2$ & 0.9002 & 1.3133 & 500 & $4.5-7.8$ & 0.8076 & 1.2979 \\
\hline 25 & 25.3.1998 & 8.1 & 2 & 128 & $4.5-6.7$ & 0.9109 & 1.3363 & 145 & $4.5-8.1$ & 0.6460 & 1.2041 \\
\hline 26 & 3.5 .1998 & 7.5 & 1 & 170 & $4.5-7.0$ & 0.9706 & 1.4620 & 181 & $4.5-7.5$ & 0.7455 & 1.4163 \\
\hline 27 & 29.11.1998 & 7.7 & 2 & 215 & $4.5-7.0$ & 0.9266 & 1.3591 & 229 & $4.5-7.7$ & 0.7646 & 1.3190 \\
\hline 28 & 17.8.1999 & 7.6 & 1 & 125 & $4.5-6.4$ & 1.1838 & 1.4286 & 150 & $4.5-7.6$ & 0.7647 & 1.4606 \\
\hline 29 & 20.9.1999 & 7.7 & 1 & 124 & $4.5-6.3$ & 1.0652 & 1.2641 & 158 & $4.5-7.7$ & 0.7859 & 1.0241 \\
\hline 30 & 26.11.1999 & 7.5 & 2 & 185 & $4.5-7.2$ & 0.7196 & 1.0828 & 210 & $4.5-7.5$ & 0.7274 & 1.0044 \\
\hline 31 & 28.3.2000 & 7.6 & 1 & 177 & $4.5-6.6$ & 1.1284 & 1.1826 & 190 & $4.5-7.6$ & 0.8116 & 1.1589 \\
\hline 32 & 4.5 .2000 & 7.6 & 2 & 251 & $4.5-6.3$ & 1.2623 & 1.4651 & 274 & $4.5-7.6$ & 0.8780 & 1.4082 \\
\hline 33 & 4.6.2000 & 7.9 & 2 & 305 & $4.5-7.6$ & 0.8958 & 1.3558 & 346 & $4.5-7.9$ & 0.7799 & 1.2767 \\
\hline 34 & 18.6.2000 & 7.9 & 2 & 294 & $4.5-7.2$ & 0.8754 & 1.0631 & 304 & $4.5-7.9$ & 0.7670 & 1.0486 \\
\hline 35 & 16.11 .2000 & 8 & 2 & 122 & $4.5-6.2$ & 0.9458 & 1.2322 & 246 & $4.5-8.0$ & 0.7096 & 0.8686 \\
\hline 36 & 17.11 .2000 & 7.8 & 2 & 246 & $4.5-7.0$ & 0.7096 & 0.8686 & 311 & $4.5-7.8$ & 0.7016 & 0.9257 \\
\hline 37 & 1.1.2001 & 7.5 & 1 & 287 & $4.5-7.0$ & 0.9740 & 1.2208 & 304 & $4.5-7.5$ & 0.8248 & 1.1673 \\
\hline 38 & 26.1.2001 & 7.7 & 1 & 188 & $4.5-7.5$ & 0.7589 & 0.9969 & 209 & $4.5-7.7$ & 0.6813 & 0.9802 \\
\hline 39 & 19.10 .2001 & 7.5 & 2 & 138 & $4.5-7.0$ & 0.8580 & 1.2671 & 150 & $4.5-7.5$ & 0.7077 & 1.1887 \\
\hline 40 & 14.11 .2001 & 7.8 & 1 & 96 & $4.5-6.0$ & 1.4578 & 1.6223 & 119 & $4.5-7.8$ & 0.6919 & 1.3893 \\
\hline 41 & 5.3 .2002 & 7.5 & 1 & 259 & $4.5-7.4$ & 0.9470 & 1.2849 & 274 & $4.5-7.5$ & 0.8065 & 1.2434 \\
\hline 42 & 19.8.2002 & 7.7 & 2 & 123 & $4.5-6.5$ & 1.0050 & 1.3875 & 135 & $4.5-7.7$ & 0.7509 & 1.2164 \\
\hline 43 & 8.9.2002 & 7.7 & 2 & 287 & $4.5-6.7$ & 0.8820 & 1.2439 & 332 & $4.5-7.7$ & 0.7886 & 1.2066 \\
\hline
\end{tabular}


Table 5 continued

\begin{tabular}{|c|c|c|c|c|c|c|c|c|c|c|c|}
\hline \multirow[t]{2}{*}{ Number } & \multirow[t]{2}{*}{ Date } & \multirow[t]{2}{*}{$M_{\mathrm{w}}$} & \multirow[t]{2}{*}{ Quadrant } & \multicolumn{4}{|c|}{$\begin{array}{l}\text { Number of earthquakes }(N) \text {, magnitude range } \\
\text { (MR) and the } b \text {-value one day before each } \\
\text { earthquake as calculated through }\end{array}$} & \multicolumn{4}{|c|}{$\begin{array}{l}\text { Number of earthquakes, magnitude range (MR) and } \\
\text { the } b \text {-value on the same day after each earthquake as } \\
\text { calculated through }\end{array}$} \\
\hline & & & & $N$ & MR & $\begin{array}{l}\text { Regression } \\
\text { method }\end{array}$ & $\begin{array}{l}\text { Max likelihood } \\
\text { method }\end{array}$ & $N$ & MR & Regression method & $\begin{array}{l}\text { Max likelihood } \\
\text { method }\end{array}$ \\
\hline 44 & 10.10 .2002 & 7.6 & 2 & 445 & $4.5-6.7$ & 0.9563 & 1.2698 & 491 & $4.5-7.6$ & 0.8493 & 1.2109 \\
\hline 45 & 15.7.2003 & 7.6 & 2 & 236 & $4.5-6.9$ & 0.9403 & 1.2030 & 257 & $4.5-7.6$ & 0.8352 & 1.1542 \\
\hline 46 & 25.9.2003 & 8.3 & 1 & 220 & $4.5-6.6$ & 1.1707 & 1.2929 & 245 & $4.5-8.3$ & 0.7054 & 1.1783 \\
\hline 47 & 17.11.2003 & 7.8 & 1 & 349 & $4.5-7.0$ & 1.0351 & 1.2434 & 402 & $4.5-7.8$ & 0.8791 & 1.2461 \\
\hline 48 & 11.11 .2004 & 7.5 & 2 & 338 & $4.5-6.9$ & 1.0071 & 1.2472 & 369 & $4.5-7.5$ & 0.9096 & 1.1621 \\
\hline 49 & 23.12 .2004 & 8.1 & 2 & 194 & $4.5-6.8$ & 1.1816 & 1.6296 & 209 & $4.5-8.1$ & 0.6800 & 1.4953 \\
\hline 50 & 26.12 .2004 & 9.1 & 1 & 238 & $4.5-8.1$ & 0.6934 & 1.5335 & 480 & $4.5-9.1$ & 0.6128 & 0.9416 \\
\hline 51 & 28.3.2005 & 8.6 & 1 & 319 & $4.5-7.1$ & 1.0186 & 1.4431 & 420 & $4.5-8.6$ & 0.6731 & 1.3363 \\
\hline 52 & 9.9.2005 & 7.6 & 2 & 359 & $4.5-7.2$ & 1.0851 & 1.4920 & 375 & $4.5-7.6$ & 0.8579 & 1.4593 \\
\hline 53 & 8.10 .2005 & 7.6 & 1 & 445 & $4.5-6.6$ & 1.3278 & 1.5972 & 565 & $4.5-7.6$ & 0.9707 & 1.4746 \\
\hline 54 & 27.1.2006 & 7.6 & 2 & 226 & $4.5-6.7$ & 1.1550 & 1.7943 & 234 & $4.5-7.6$ & 0.7925 & 1.7224 \\
\hline 55 & 20.4.2006 & 7.6 & 1 & 314 & $4.5-6.5$ & 1.1948 & 1.2829 & 336 & $4.5-7.6$ & 0.9118 & 1.2191 \\
\hline 56 & 17.7.2006 & 7.7 & 2 & 329 & $4.5-6.3$ & 1.2034 & 1.5514 & 434 & $4.5-7.7$ & 0.9742 & 1.2787 \\
\hline 57 & 15.11 .2006 & 8.3 & 1 & 366 & $4.5-6.7$ & 1.1050 & 1.3846 & 532 & $4.5-8.3$ & 0.8491 & 1.2329 \\
\hline 58 & 13.1.2007 & 8.1 & 1 & 336 & $4.5-7.1$ & 0.9912 & 1.3841 & 413 & $4.5-8.1$ & 0.7646 & 1.3435 \\
\hline 59 & 21.1.2007 & 8.1 & 1 & 477 & $4.5-7.5$ & 0.7870 & 1.3522 & 545 & $4.5-8.1$ & 0.7668 & 1.2630 \\
\hline 60 & 1.4.2007 & 8.1 & 2 & 346 & $4.5-7.1$ & 1.0130 & 1.3010 & 395 & $4.5-8.1$ & 0.7844 & 1.1353 \\
\hline 61 & 8.8.2007 & 7.5 & 2 & 378 & $4.5-7.2$ & 1.0096 & 1.2638 & 396 & $4.5-7.5$ & 0.8652 & 1.2390 \\
\hline 62 & 12.9.2007 & 8.5 & 2 & 397 & $4.5-7.2$ & 1.0581 & 1.3512 & 446 & $4.5-8.5$ & 0.6551 & 1.2718 \\
\hline 63 & 28.9.2007 & 7.5 & 1 & 507 & $4.5-7.2$ & 0.9917 & 1.0997 & 556 & $4.5-7.5$ & 0.8684 & 1.0588 \\
\hline 64 & 12.5.2008 & 7.9 & 1 & 369 & $4.5-7.1$ & 1.0175 & 1.3146 & 505 & $4.5-7.9$ & 0.9088 & 1.3332 \\
\hline 65 & 5.7.2008 & 7.7 & 1 & 369 & $4.5-6.9$ & 1.1382 & 1.3827 & 382 & $4.5-7.7$ & 0.9052 & 1.3543 \\
\hline 66 & 3.1 .2009 & 7.7 & 2 & 343 & $4.5-6.4$ & 1.2027 & 1.1692 & 388 & $4.5-7.7$ & 0.8902 & 1.1086 \\
\hline 67 & 15.7.2009 & 7.8 & 2 & 239 & $4.5-6.7$ & 1.1900 & 1.2643 & 273 & $4.5-7.8$ & 0.8710 & 1.1988 \\
\hline 68 & 10.8.2009 & 7.5 & 1 & 281 & $4.5-7.1$ & 1.0791 & 1.2415 & 293 & $4.5-7.5$ & 0.8353 & 1.1804 \\
\hline 69 & 30.9.2009 & 7.6 & 2 & 232 & $4.5-7.0$ & 1.0206 & 1.2198 & 245 & $4.5-7.6$ & 0.8168 & 1.1603 \\
\hline 70 & 7.10.2009 & 7.8 & 2 & 267 & $4.5-7.6$ & 0.8615 & 1.1893 & 303 & $4.5-7.8$ & 0.6827 & 1.0091 \\
\hline 71 & 6.4 .2010 & 7.8 & 1 & 256 & $4.5-6.7$ & 0.9668 & 1.2735 & 264 & $4.5-7.8$ & 0.8468 & 1.2249 \\
\hline 72 & 12.6.2010 & 7.5 & 1 & 266 & $4.5-7.1$ & 0.9618 & 1.3671 & 280 & $4.5-7.5$ & 0.7978 & 1.3118 \\
\hline 73 & 23.7.2010 & 7.6 & 1 & 332 & $4.5-7.3$ & 0.9945 & 1.2955 & 354 & $4.5-7.6$ & 0.7977 & 1.1946 \\
\hline 74 & 25.10 .2010 & 7.8 & 2 & 222 & $4.5-6.3$ & 1.3670 & 1.5626 & 249 & $4.5-7.8$ & 0.8504 & 1.4136 \\
\hline
\end{tabular}

and their recalculated values in Tables 5, 6 and (iv) $b$ results also show some variations between the use of moving and expanding time windows utilizing the same technique, though correlatable results are mostly obtained, see, for example, Figs. 5 and 7.

The minimum values obtained after the occurrence of all major earthquakes of this study cannot be debated, as the occurrence of one or more large earthquakes leads to a reduction of the $b$. Nevertheless, several questions remain. Was this value a maximum before the earthquake occurrence? The answer is evidenced from the results of both the expanding (cumulative) and the moving time window analysis of Sects. 4.1, 4.2 and 4.3. Detailed $b$-calculations for many days before and after four major earthquakes shown in Figs. 3, 5 and 7 demonstrate how the $b$-value starts increasing many days before the date of occurrence. Small foreshocks generally result in increase of the $b$ value, while relatively large foreshocks result in reducing it, accompanied by small amounts and/or a reduction in their rate of increase, depending on their numbers and magnitudes. Thus, the rate of $b$-increase also shows a clear variation with time. Up to only a few days before the major earthquake, the rate appears to decrease to a minimum; in other cases its value is reduced to zero or attains a small negative number. On the occurrence of the major earthquake, it drops down to a minimum and starts increasing 
Table 6 The $b$-values for all earthquakes that occurred within the western hemisphere during the period 1990-2010 with magnitudes $\geq 7.3$ as calculated 1 day before and after their occurrences, utilizing both the least-square regression and the maximum likelihood methods

\begin{tabular}{|c|c|c|c|c|c|c|c|c|c|c|c|}
\hline \multirow[t]{2}{*}{ Number } & \multirow[t]{2}{*}{ Date } & \multirow[t]{2}{*}{$M_{\mathrm{w}}$} & \multirow[t]{2}{*}{ Quadrant } & \multicolumn{4}{|c|}{$\begin{array}{l}\text { Number of earthquakes }(N) \text {, magnitude range } \\
\text { (MR) and the } b \text {-value one day before each } \\
\text { earthquake as calculated through }\end{array}$} & \multicolumn{4}{|c|}{$\begin{array}{l}\text { Number of earthquakes, magnitude range (MR) } \\
\text { and the } b \text {-value on the same day after each } \\
\text { earthquake as calculated through }\end{array}$} \\
\hline & & & & $N$ & MR & $\begin{array}{l}\text { Regression } \\
\text { method }\end{array}$ & $\begin{array}{l}\text { Max likelihood } \\
\text { method }\end{array}$ & $N$ & MR & $\begin{array}{l}\text { Regression } \\
\text { method }\end{array}$ & $\begin{array}{l}\text { Max likelihood } \\
\text { method }\end{array}$ \\
\hline 1 & 25.3.1990 & 7.3 & 4 & 96 & $4.5-6.4$ & 1.0616 & 1.2085 & 104 & $4.5-7.3$ & 0.8493 & 1.0805 \\
\hline 2 & 22.4.1991 & 7.6 & 4 & 101 & $4.5-6.9$ & 0.7601 & 0.9683 & 113 & $4.5-7.6$ & 0.7163 & 0.9173 \\
\hline 3 & 23.6.1991 & 7.3 & 3 & 102 & $4.5-7.0$ & 0.7031 & 0.9171 & 107 & $4.5-7.3$ & 0.6421 & 0.8751 \\
\hline 4 & 28.6.1992 & 7.3 & 4 & 107 & $4.5-6.5$ & 0.8898 & 0.9503 & 116 & $4.5-7.3$ & 0.8037 & 0.9093 \\
\hline 5 & 2.9.1992 & 7.7 & 4 & 102 & $4.5-6.9$ & 0.8538 & 0.8113 & 150 & $4.5-7.7$ & 0.7920 & 0.8686 \\
\hline 6 & 9.3 .1994 & 7.6 & 3 & 90 & $4.5-6.7$ & 1.0397 & 0.9845 & 94 & $4.5-7.6$ & 0.7196 & 0.9153 \\
\hline 7 & 9.6 .1994 & 8.2 & 3 & 133 & $4.5-6.9$ & 0.9183 & 0.9891 & 137 & $4.5-8.2$ & 0.6703 & 0.9196 \\
\hline 8 & 7.4.1995 & 7.4 & 3 & 93 & $4.5-6.3$ & 0.9097 & 1.0987 & 99 & $4.5-7.4$ & 0.8580 & 1.0383 \\
\hline 9 & 30.7 .1995 & 8.0 & 3 & 106 & $4.5-7.2$ & 0.8586 & 1.2647 & 159 & $4.5-8.0$ & 0.6457 & 1.1885 \\
\hline 10 & 14.9.1995 & 7.4 & 4 & 171 & $4.5-6.6$ & 0.9340 & 0.9875 & 177 & $4.5-7.4$ & 0.8981 & 0.9621 \\
\hline 11 & 9.10 .1995 & 8.0 & 4 & 177 & $4.5-7.4$ & 0.7878 & 0.9830 & 188 & $4.5-8.0$ & 0.6738 & 0.9617 \\
\hline 12 & 21.2.1996 & 7.5 & 3 & 158 & $4.5-6.6$ & 0.9010 & 1.2684 & 165 & $4.5-7.5$ & 0.7703 & 1.2207 \\
\hline 13 & 10.6.1996 & 7.9 & 4 & 110 & $4.5-7.0$ & 0.8213 & 1.3344 & 166 & $4.5-7.9$ & 0.6988 & 1.1722 \\
\hline 14 & 5.8.1996 & 7.4 & 3 & 99 & $4.5-6.8$ & 0.8335 & 1.4574 & 108 & $4.5-7.4$ & 0.7438 & 1.2183 \\
\hline 15 & 12.11 .1996 & 7.7 & 3 & 170 & $4.5-6.9$ & 1.0972 & 1.2346 & 188 & $4.5-7.7$ & 0.8194 & 1.1731 \\
\hline 16 & 14.10 .1997 & 7.8 & 3 & 165 & $4.5-7.0$ & 0.9096 & 1.1558 & 179 & $4.5-7.8$ & 0.7494 & 1.1266 \\
\hline 17 & 30.9.1999 & 7.5 & 4 & 85 & $4.5-6.4$ & 0.9592 & 1.4945 & 92 & $4.5-7.5$ & 0.6887 & 1.3590 \\
\hline 18 & 13.1.2001 & 7.7 & 4 & 161 & $4.5-7.0$ & 0.8939 & 0.9765 & 165 & $4.5-7.7$ & 0.7527 & 0.9379 \\
\hline 19 & 23.6.2001 & 8.4 & 3 & 77 & $4.5-7.2$ & 0.7501 & 1.1816 & 104 & $4.5-8.4$ & 0.6071 & 0.8944 \\
\hline 20 & 7.7.2001 & 8.4 & 3 & 286 & $4.5-8.4$ & 0.7422 & 1.0139 & 318 & $4.5-8.4$ & 0.7055 & 1.0222 \\
\hline 21 & 19.8.2002 & 7.7 & 3 & 145 & $4.5-6.5$ & 1.0376 & 1.2180 & 152 & $4.5-7.7$ & 0.7746 & 1.1561 \\
\hline 22 & 3.11 .2002 & 7.9 & 4 & 147 & $4.5-6.9$ & 0.8099 & 1.2253 & 178 & $4.5-7.9$ & 0.7800 & 1.1435 \\
\hline 23 & 22.1 .2003 & 7.6 & 4 & 118 & $4.5-6.5$ & 0.8972 & 1.0458 & 126 & $4.5-7.6$ & 0.7508 & 0.9406 \\
\hline 24 & 4.8.2003 & 7.6 & 3 & 136 & $4.5-6.6$ & 1.0443 & 1.2382 & 164 & $4.5-7.6$ & 0.7861 & 1.2196 \\
\hline 25 & 13.6.2005 & 7.8 & 3 & 244 & $4.5-6.6$ & 0.9420 & 1.4301 & 253 & $4.5-7.8$ & 0.8272 & 1.3838 \\
\hline 26 & 26.9.2005 & 7.5 & 3 & 110 & $4.5-6.6$ & 1.3028 & 1.5166 & 114 & $4.5-7.5$ & 0.7246 & 1.4105 \\
\hline 27 & 2.1 .2006 & 7.4 & 3 & 182 & $4.5-6.7$ & 1.0864 & 1.3511 & 197 & $4.5-7.4$ & 0.7968 & 1.2656 \\
\hline 28 & 3.5 .2006 & 8.0 & 3 & 266 & $4.5-6.7$ & 1.1140 & 1.0776 & 289 & $4.5-8.0$ & 0.7616 & 1.0691 \\
\hline 29 & 15.8.2007 & 8.0 & 3 & 278 & $4.5-6.7$ & 1.1635 & 1.0857 & 293 & $4.5-8.0$ & 0.7766 & 1.0639 \\
\hline 30 & 14.11 .2007 & 7.7 & 3 & 261 & $4.5-6.3$ & 1.3083 & 1.3526 & 283 & $4.5-7.7$ & 0.8863 & 1.2870 \\
\hline 31 & 29.11 .2007 & 7.7 & 4 & 217 & $4.5-7.7$ & 0.8509 & 0.9716 & 230 & $4.5-7.7$ & 0.8091 & 0.9632 \\
\hline 32 & 9.12 .2007 & 7.8 & 3 & 277 & $4.5-7.7$ & 0.8393 & 0.9958 & 287 & $4.5-7.8$ & 0.7480 & 0.9892 \\
\hline 33 & 19.3.2009 & 7.6 & 3 & 240 & $4.5-7.0$ & 0.9897 & 1.0723 & 258 & $4.5-7.6$ & 0.8195 & 1.0681 \\
\hline 34 & 28.5.2009 & 7.3 & 4 & 144 & $4.5-6.5$ & 1.0926 & 1.1069 & 154 & $4.5-7.3$ & 0.9098 & 1.0616 \\
\hline 35 & 29.9.2009 & 8.1 & 3 & 98 & $4.5-6.4$ & 0.9665 & 1.1989 & 178 & $4.5-8.1$ & 0.7038 & 1.0475 \\
\hline 36 & 27.2.2010 & 8.8 & 3 & 171 & $4.5-6.1$ & 1.1457 & 1.1496 & 418 & $4.5-8.8$ & 0.7298 & 0.9196 \\
\hline 37 & 4.4.2010 & 7.2 & 4 & 692 & $4.5-6.9$ & 1.1170 & 1.3286 & 706 & $4.5-7.2$ & 1.1038 & 1.3075 \\
\hline
\end{tabular}

The total number of earthquakes used in each $b$-calculation and their magnitude ranges are also tabulated. Most numbers varied in the range 100-293. Only seven earthquakes had $N=100$. Standard deviations for all $b$-calculations varied mostly in the range \pm 0.008 to \pm 0.098

again at a relatively high and variable rate thereafter. The moving fixed-time window results also show the temporal $b$-variations, reductions in their values caused by foreshocks and aftershocks and minimum values upon the occurrence of major earthquakes. In this calculation technique, more $b$-variations are noticed not only due to the length of the time window and the number of earthquakes within it, but also due to dropping off of events from the 


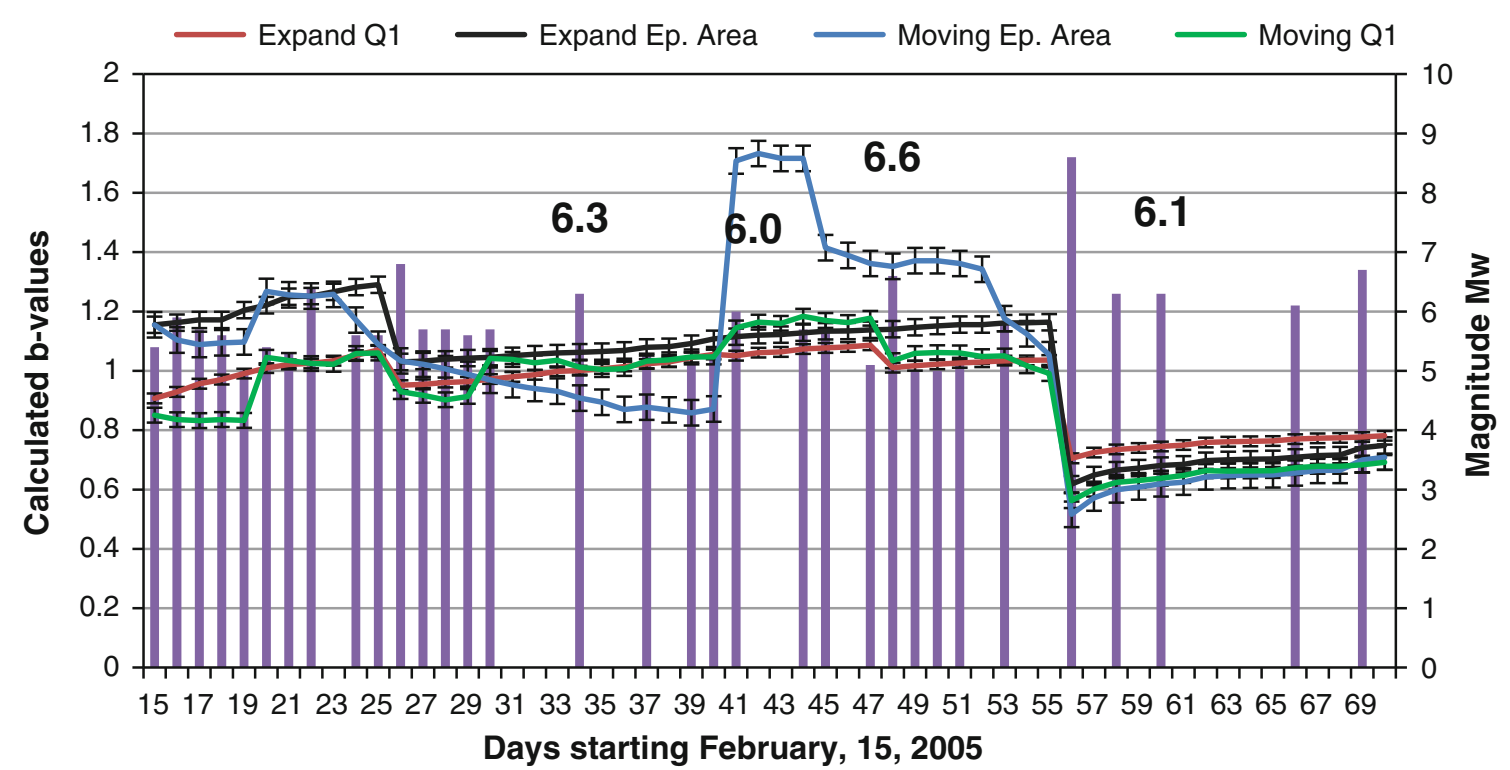

Fig. 7 Calculated $b$-values for Quadrant 1 (red) and the epicentral area (black) of the Sumatra $2005 M_{\mathrm{w}}=8.6$ utilizing 1 day expanding time windows. The first window expands between Feb. 8 and Feb. 15, while the last expands between Feb. 8 and April 112005 . The green and blue curves represent the calculated $b$-values for both regions utilizing a 15 day window that moves 1 day at a time. All epicentral earthquakes $M \geq 5$ are marked. Only 4 earthquakes $\left(M_{\mathrm{w}} \geq 6\right)$ occurred outside Sumatra epicentral region, but within Quadrant 1 are marked with their magnitudes

moving windows. Dropping a large earthquake when the window passes by it results in a high jump in the $b$-value. The process of relatively large foreshocks coming into and out of moving windows and the occurrence of foreshocks appears to explain the noticeable $b$-reductions days before some large earthquakes. In every case, the $b$-value drops down to a minimum on the occurrence of large earthquakes and their immediate aftershocks. Expanding the length of the window from a fixed starting time helps to avoid this, as all past earthquakes within the successive windows will remain within it and thus the $b$-changes will be mainly affected by the incoming earthquakes as the window expands.

The calculated $b$-values strongly demonstrate the local and regional nature of variations; see Tables 4 and 5 . The Chile earthquake of 2010 resulted in $b$-reduction in quadrant 3, the left hemisphere and the whole Earth by the amounts $\Delta b=0.350,0.416$ and 0.293 , respectively. The 25 October 2010 earthquake that occurred in quadrant 2 resulted in a reduction in $b$-value by 0.546 , the right hemisphere by 0.515 and the whole Earth by 0.351 . Both cases demonstrate the regional nature of $b$-variations. The $b$-variations of the epicentral area of the Sumatra 2005 earthquake are plotted on Fig. 7 together with those of quadrant 1 for a period of about 45 days before and 10 days after its occurrence utilizing moving and expanding (cumulative) windows. The two expanding curves (red and black) appear to correlate with each other showing the local and regional nature of these variations. These results indicate that the $b$-values of quadrant 1 and their variations were mainly controlled by the same factors as those in the Sumatra epicentral area during this period of time. Upon the occurrence of the major earthquake (M8.6), the $b$-value of the epicentral area got reduced by 0.546 and that of quadrant 1 by 0.331 . The $M 6.8$ foreshock that occurred on February 26 resulted in a reduction of the $b$-value of the epicentral area by 0.260 and that of quadrant 1 by 0.119 . The $M 6.6$ earthquake $\left(33.8^{\circ} \mathrm{N}, 130.13^{\circ} \mathrm{E}\right)$ that occurred on March 20 outside the Sumatra epicentral area resulted in lowering the $b$-value of quadrant 1 by 0.085 . A small deviation is observed in the $b$-curve for the Sumatra earthquake showing that the $b$-gradient was reduced on that day. A possible relation may be inferred as two small foreshocks occurred in Sumatra region that day with magnitudes 4.5 and 4.6. Note that during the last 2 days before the 8.6 major earthquake, the rate of $b$-increase of quadrant 1 got reduced to less than $0.001 /$ day, while that of the epicentral area reduced to about $0.0013 /$ day.

The blue and green curves of Fig. 7 represent the $b$ variations as calculated for both epicentral region and quadrant 1 , utilizing a 15-day window that moves daily starting 15 February 2005. Both curves show a reasonable correlation and large $b$-variations. The epicentral values (blue) vary from a maximum of 1.732 on March 13 to a minimum of 0.517 on March 28 soon after the occurrence of the M8.6 earthquake. Between March 13 and 27, the $b$ value appears to reduce almost continuously to 1.054 one day before the major earthquake. On March 13, its value jumped from 0.871 the day before, simply because on that day the M6.8 foreshock of February 26 dropped off the 
moving window. The continuous decrease beyond March 13 appears to correlate with the marked foreshocks, where the M6.6 foreshock of March 20 shows the largest effect. The following three days exhibit a $b$-increase. A sharp decrease is observed soon after, which might be caused by the M5.8 earthquake of March 25 and other smaller magnitude events. The quadrant 1 curve (green) shows the same behaviour with the removal of the 6.8 event and the addition of the M6.6, M5.8 and other foreshocks. The $b$ value reduced to 0.991 on March 27 and to 0.563 on the occurrence of the M8.6 earthquake. Following that, both curves show gradual increase, good correlation and some deviations that correlate with the occurrence of aftershocks.

The $b$-variations with time and region as deduced from this study are largely agreed upon amongst seismologists. Various factors that influence $b$-value have been suggested, including tectonic environment, data quality and completeness, magnitude type, stress conditions, fluid and pore pressure, crustal heterogeneity, geothermal conditions, depth and other geophysical and geotectonic characteristics. The $b$-variations of Sects. 4.1, 4.2 and 4.3 represent mainly the Earth as a whole, its two hemispheres and four quadrants as well as epicentral regions of some selected large earthquakes. Thus, the $b$-variations based entirely on tectonic region are excluded on the basis of the size of the region considered. Furthermore, the regional character of the calculated $b$-variations eliminates most of the above mentioned factors. Fluid and pore pressure have been claimed to affect the $b$-variations mainly in volcanic regions (e.g. Wiemer and Wyss 1997, 2002; Wiemer et al. 1998; Wyss et al. 2004; Wyss and Matsumura 2006; Wyss and Stefansson 2006; Lin et al. 2007; Murru et al. 1999, 2005, 2007). Such volcanic regions, however, represent only small parts of the Earth. Considering the two hemispheres and the four quadrants of the Earth, no clear heterogeneity occurs between these mentioned units that may account for the $b$-variations. Geothermal, geophysical and other geological factors are also eliminated as the variations of these factors are mostly of local character and are much reduced when the Earth is considered as one unit or two hemispheres or even four quadrants. The seismicity data used in these calculations are taken from three reliable seismicity sources and the majority of earthquakes are reported with $M_{\mathrm{w}}$.

To eliminate the possible $b$-variations caused by using different calculation methods, the results of the least-square regression method were mainly considered. Using the same method may result in different $b$-values for the same seismicity data depending on the length of the time window, fixed, moving or expanding and the way of moving it. To eliminate much of these effects, it is found to be more suitable in the study of $b$-variations to take equal time windows in succession and/or expanding time windows that have a common starting point rather than overlapping moving windows.
Tectonic stress thus appears to be the most important factor that controls $b$-variations. The question remains: does the $b$-value increase or decrease with the applied stress? An increase in the applied stress or effective stress is believed by many researchers to result in a $b$-decrease and vice versa (e.g. Wiemer and Wyss 1997; Wiemer et al. 1998; Zuniga and Wyss 2001; Gerstenberger et al. 2001; Wiemer and Wyss 1997; Wiemer and Wyss 2002; Schorlemmer 2004, Schorlemmer et al. 2005; Wyss et al. 2004; Wyss and Matsumura 2006; Wyss and Stefansson 2006). This is also evidenced by some limited laboratory experiments (e.g. Mogi 1962; Scholz 1968). Other studies, however, report that the $b$-value increases with stress before a major earthquake and decreases thereafter (e.g. Fiedler 1974; Robinson 1979; Smith 1981, 1986; Wyss 1990; Sahie and Saikia 1994). The $b$-variations as deduced in sections (I, II and III) strongly suggest that the $b$-value increases with stress. Many days before major earthquakes, the $b$ starts increasing at relatively high rate, which varies with time and gets reduced with the occurrence of large foreshocks. In some cases this gradual $b$-increase continues to the time of occurrence of the major earthquake. In others, the rate of $b$-increase appears to be reduced within the last few days before the mainshock, and in some cases it gets reduced to zero or less. On the occurrence of a large earthquake the $b$-value gets reduced to a minimum i.e. minimum stress as much of it was accommodated by the breaking and displacement of the subsurface rocks (earthquake) and through releasing the seismic energy. Soon after that the $b$-value starts increasing again at a relatively high gradient, i.e. stress buildup again at a high rate and at variable rates thereafter, depending on the tectonic situation.

As stresses causing large earthquakes are of regional character, such stresses will act on huge volumes of subsurface rocks that extend over many $10-100 \mathrm{~s} \mathrm{~km}$ or more. The involved rocks at such scale are not homogeneous and are thus of different characteristics and shear strengths. Those weak rocks will start breaking, resulting in small magnitude and local foreshocks that result in increases in the $b$-value. The higher the stress buildup, the more foreshocks with variable sizes one would expect depending on the inhomogeneity of the rocks and the stress nature. But why did the limited laboratory results (Mogi 1962; Scholz 1968) show that with the stress increase $b$ decreases? A possible answer is that the rock specimen does not necessarily represent the rocks in nature in their inhomogeneity. Rocks in nature are much more heterogeneous than small laboratory rock samples; furthermore, the stress direction, complexity and other characteristics are mostly different.

The regional tectonic stresses acting on the subsurface rocks add to their original heterogeneity by affecting their porosity and deforming them by faulting, folding, cracking, fracturing and micro fracturing which will also affect their 
liquid contents and physical properties. Geothermal and volcanic activities also affect the physical properties of the rocks as well as the stresses acting on them and will ultimately add to their inhomogeneity. In general, geotectonic stresses tend to increase the heterogeneity of rocks with time as it does to the $b$-value. This is in agreement with the results of many previous studies (e.g. Mogi 1962; Wiemer and Wyss 1997; Wiemer et al. 1998; Power et al. 1998; Mishra et al. 2007; Singh et al. 2008; Amorese et al. 2010).

Accepting the inference that stress increases the $b$-value requires a quantitative measure to the relation between the applied stresses, the rate of $b$-increase and the resulting seismic energy. To this, the seismicity data were reinvestigated in search for those large earthquakes which had magnitudes (1.0-1.5-2.0) units larger than the largest foreshock. Some fifteen earthquakes were selected, all with magnitudes $M_{\mathrm{w}} \geq 7.0$, representing different quadrants and hemispheres of the Earth as well as epicentral regions. For each earthquake, the $b$-value was recalculated three or four times as follows: the Sumatra 9.1 earthquake of 2004 occurred in Quadrant 1. During the period 1-26 December 2004, some 332 earthquakes have occurred in quadrant 1 with magnitudes $\geq 4.5$. Only 2 earthquakes occurred with $M_{\mathrm{w}} \geq 7$ and only one had $M_{\mathrm{w}} \geq 7.5$ which is the 9.1 earthquake. In the regression analysis, 10 points are involved whose x-values start with $M_{\mathrm{w}}=4.5,5,5.5, \ldots 9$, their $y$-values represent $\log (N)$, where $N$ is the number of earthquakes which is equal zero for the last 4 points in this case. Considering the 10 points gives a $b$-value of 0.6124 . Omitting the 10th point, i.e. assuming the magnitude of this earthquake 8.5 gives a $b$-value of 0.7005 . Omitting the 9 th and 8th points gives $b$-values of 0.7985 and 0.8944 , respectively. This implies that if the magnitude of this earthquake was 8 instead of 9.1 , the $b$-value will be reduced to 0.7985 instead of 0.6124 , a difference of $(0.186 / 1$ magnitude unit). The same process was repeated for the other 14 selected earthquakes. It is found that all results gave $b$ variations in the range (0.18-0.27/1 magnitude degree). Most values are in the range (0.18-0.23/1 magnitude degree). These results may, therefore, be taken to indicate that an increase in the $b$-value of about 0.20 implies a stress increase that may produce a one unit higher magnitude which will increase the seismic energy some 28-30 times.

\section{Conclusions}

Detailed $b$-calculations for the seismicity data of the Earth, its two eastern and western hemispheres and four quadrants and the epicentral regions of some selected large earthquakes that occurred during the period 1990-2011 with magnitudes $\geq 4.5$, as obtained from NEIC, IRIS and ISC catalogues reveal the following:
(1) Continuous cyclic $b$-variations of the whole Earth, its two hemispheres and four quadrants are clearly evidenced from studying long time (1 year-many years) and short time (days-weeks) seismicity data. These variations are observed to occur not only on yearly or monthly basis, but also daily, particularly before and after the occurrence of large earthquakes. The short time $b$-variations may exceed $\pm(0.6-0.7)$ of its absolute value within a few weeks or less, while the long time variations are less. The $b$-value always attains maxima and minima before and after the occurrence of all large earthquakes irrespective of the used method of calculation and how it is applied. The $b$-values of the whole Earth, its two hemispheres, four quadrants and the epicentral regions start increasing many days before each large earthquake at variable gradients. In proximity to the day of occurrence, mostly within a few days, the rate of increase reduces gradually. In some cases, it is reduced to zero or to small negative values in others. This is largely influenced by the occurrence of foreshocks, particularly the relatively large ones.

(2) Though reasonably correlatable $b$-variations are obtained from both the regression and the maximum likelihood methods, it is found that $b$-variations are not only influenced by the different calculation techniques, but also the way of using the same technique. Use of moving, fixed or expanding time windows influences not only the number of earthquakes, but also their size distribution. Use of an expanding time window that starts at a fixed time appears to be a more effective technique to study the $b$-value and its variations, as this retains all concerned earthquakes and their time distribution within the studied time. In the moving-window technique, adding and dropping off large foreshocks and aftershocks results in relatively high $b$-variations.

(3) In the case of large earthquakes, the deduced $b$ variations appear to be of both local and regional character as deduced from the observed correlation between the $b$-curves of the epicentral area and quadrant 1 of Fig. 7, particularly the expandingwindow results. The moving-window results also show a reasonably high correlation. Further, correlation is observed between the $b$-variations of the whole Earth and its two hemispheres, Figs. 1 and 2. This may be taken to indicate that in the case of large earthquakes, the geodynamic processes acting within an epicentral region appear to influence the concerned quadrant, hemisphere and the Earth as a whole.

(4) Many factors have been reported to influence the $b$-value and its temporal and spatial variations. These include stress, heterogeneity, depth, fluid and pore pressure, latent 
heat, regional geological and geotectonic factors. As the calculated $b$-variations represent the Earth as a whole, its two hemispheres and four quadrants, the regional factors are excluded and the effects of much of the others are eliminated. Stress is inferred to be the most important factor to affect the $b$ and its variations as firstly, stress causes deformation of rocks including brittle failure i.e. earthquakes, and secondly, all other factors are directly related to and influenced by the stress.

(5) The results of this study indicate that the $b$-value appears to increase with the regional stress buildup. The epicentral rocks with lower shear strength will start breaking giving local small and intermediate magnitude foreshocks, which will result in increasing the $b$-value and changing its gradient. Though, on the occurrence of relatively large foreshocks an immediate reduction in the $b$-value occurs. As the stress buildup continues, the $b$-value continues to increase at a rate that is controlled by the stress itself. This will lead to more foreshocks with variable magnitudes. The higher the heterogeneity of the rocks of the epicentral region, the more small and intermediate foreshocks one would expect, which implies a $b$-increase and some variation. It is unfortunate that in many cases these small foreshocks are not recorded, which keeps the calculated $b$-values in error. Such small foreshocks are mostly missed in laboratory experiments as the rock samples do not represent the actual heterogeneity of the true Earth. On the occurrence of every major earthquake, the $b$-value gets reduced noticeably. Soon after that it starts increasing once again at variable rates depending on the stress conditions.

(6) It is found that for earthquakes with magnitudes $M_{\mathrm{w}} \geq 7.0$, an increase of about 0.20 in the $b$-value implies a stress increase that will result in an earthquake with a magnitude one unit higher, i.e. increasing the seismic energy some 28-30 times.

\begin{abstract}
Acknowledgments This work was completed during a sabbatical the author spent at the University of Calgary with financial support from the University of Jordan, Amman. Thanks are due to Dave Eaton of UC for many useful discussions through the preparation of this work and to Stephen Gao, Missouri University of Science \& Technology and to Keith Nakanishi of the USGS for their critical reading of the manuscript.
\end{abstract}

\section{References}

Aki K (1965) Maximum likelihood estimate of $\mathrm{b}$ in the formula $\log$ $N=a-b M$ and its confidence limits. Bull Earthq Res Inst Tokyo Univ 43:237-239

Amelung F, King G (1997) Earthquake scaling laws for creeping and non-creeping faults. Geophys Res Lett 24(5):507-510
Amorese D, Grasso J, Rydelek P (2010) On varying $b$-values with depth: results from computer-intensive tests for Southern California. Geophys J Int 180(1):347-360

Beauval C, Scotti O (2004) Quantifying sensitivities of PSHA for France to earthquake catalog uncertainties, truncation of groundmotion variability, and magnitude limits. Bull Seismol Soc Am 94(5): 1579

Cao A, Gao S (2002) Temporal variation of seismic b-values beneath northeastern Japan island arc. Geophys Res Lett 29(9):48-51

Console R, Murru M, Catalli F, Falcone G (2007) Real time forecasts through an earthquake clustering model constrained by the rateand-state constitutive law: comparison with a purely stochastic ETAS model. Seismol Res Lett 78(1):49

Del Pezzo E, Esposito A, Giudicepietro F, Marinaro M, Martini M, Scarpetta S (2003) Discrimination of earthquakes and underwater explosions using neural networks. Bull Seismol Soc Am 93(1):215

El-Isa ZH, Eaton D (2013) Spatiotemporal variations in the $b$-value of earthquake magnitude-frequency distributions: classification and causes. Tectonophysics, in print

Fiedler G (1974) Local $b$-values related to seismicity. Tectonophysics 23(3):277-282

Frohlich C, Davis S (1993) Teleseismic b values; or, much ado about 1.0. J Geophys Res 98(B1):631-644

Gerstenberger M, Wiemer S, Giardini D (2001) A systematic test of the hypothesis that the $\mathrm{b}$ value varies with depth in California. Geophys Res Lett 28(1):57-60

Ghosh A, Vidale J, Peng Z, Creager K, Houston H (2008) Complex nonvolcanic tremor near Parkfield, California, triggered by the great 2004 Sumatra earthquake. J Geophys Res 114:B00A06

Gibowicz S (1973) Variation of the frequency-magnitude relation during earthquake sequences in New Zealand. Bull Seismol Soc Am 63(2):517

Gibowicz S, Lasocki S (2001) Seismicity induced by mining: ten years later. Adv Geophys 44:39-181

Gutenberg B, Richter C (1954) Seismicity of the earth and associated phenomena, vol 2. Princeton University Press, Princeton

Gutenberg B, Richter C (1944) Frequency of earthquakes in California. Bull Seismol Soc Am 34(4):185

Guttorp P (1987) On least-squares estimation of $b$ values. Bull Seismol Soc Am 77(6):2115

Imoto M (1991) Changes in the magnitude-frequency $b$-value prior to large (M 6.0) earthquakes in Japan. Tectonophysics 193(4): $311-325$

Ishibe T, Tsuruoka H, Shimazaki K (2008) The dependency of the $b$ value on the focal mechanism and on the hypocentral depth. Paper presented at the meeting of the Japan Geoscience Union Meeting, Chiba, Japan, May 2008

Ishimoto M, Iida K (1939) Observations of earthquakes registered with the microseismograph constructed recently. Bull Earthq Res Inst 17:443-478

Jackson D, Kagan Y (1999) Testable earthquake forecasts for 1999. Seismol Res Lett 70(4):393-403

Jaume S, Sykes L (1999) Evolving towards a critical point: a review of accelerating seismic moment/energy release prior to large and great earthquakes. Pure Appl Geophys 155(2):279-306

Lin J, Sibueti J, Lee C, Hsu S, Klingelhoefer F (2007) Special variations in the frequency-magnitude distribution of earthquakes in the southwestern Okinawa trough. Earth Planets Space 59:221-225

Mishra O, Kayal J, Chakrabortty G, Singh O, Ghosh D (2007) Aftershock investigation in the Andaman-Nicobar Islands of India and its seismotectonic implications. Bull Seismol Soc Am 97(1A):S71 
Mogi K (1962) Study of elastic shocks caused by the fracture of heterogeneous materials and its relations to earthquake phenomena. Bull Earthq Res 40(1):125-173

Mogi K (1967) Earthquakes and fractures. Tectonophysics 5(1):35-55

Mori J, Abercrombie R (1997) Depth dependence of earthquake frequency-magnitude distributions in California: implications for rupture initiation. J Geophys Res 102(15):081-115

Murru M, Montouri C, Wyss M, Privetera E (1999) The locations of magma chambers at Mt. Etna, Italy, mapped by b-values. Geophys Res Lett 26:2553-2556

Murru M, Montouri C, Console R, Lisi A (2005) Mapping of the b value anomalies beneath Mt. Etna, Italy, during July-August 2001 lateral eruption. Geophys Res Lett 32 L05309. doi:10. 1029/2004GL021545

Nuannin P, Kulhanek O, Persson L (2005) Spatial and temporal $b$ value anomalies preceding the devastating off coast of NW Sumatra earthquake of Dec 26, 2004. Geophys Res Lett 32(11): L11307

Ogata Y, Imoto M, Katsura K (1991) 3-D spatial variation of $b$-values of magnitude-frequency distribution Beneath the Kanto District, Japan. Geophys J Int 104(1):135-146

Power J, Wyss M, Latchman J (1998) Spatial variations in the frequency-magnitude distribution of earthquakes at Soufriere Hills Volcano, Montserrat, West Indies. Geophys Res Let 25(19): 3653-3656

Robinson R (1979) Variation of energy release, rate of occurrence and b-value of earthquakes in the Main Seismic Region, New Zealand. Phys Earth Planet Inter 18(3):209-220

Sahie O, Saikia M (1994) The $b$ value before the 6th August, 1988 India-Myanmar Border Region Earthquake-a case study. Tectonophysics 234(4):349-354

Scholz C (1968) Microfracturing and the inelastic deformation of rock in compression. J Geophys Res 73(4):1417-1432

Schorlemmer D, Wiemer S, Wyss M (2004) Earthquake statistics at Parkfield: 1. Stationarity of b values. J Geophys Res 109:B12307

Schorlemmer D, Wiemer S, Wyss M (2005) Variations in earthquakesize distribution across different stress regimes. Nature 437(7058): $539-542$

Shi Y, Bolt B (1982) The standard error of the magnitude-frequency b value. Bull Seismol Soc Am 72(5):1677

Singh S, Carton H, Tapponnier P, Hananto N, Chauhan A, Hartoyo D, Bayly M, Moeljopranoto S, Bunting T, Christie P, Lubis H, Martin J (2008) Seismic evidence for broken oceanic crust in the 2004 Sumatra earthquake epicentral region. Nat Geosci 1(11):777-781

Smith W (1981) The $b$-value as an earthquake precursor. Nature 289: 136-139

Smith W (1986) Evidence for precursory changes in the frequencymagnitude $b$-value. Geophys J Roy Astron Soc 86(3):815-838

Stein S, Wysession M (2003) An introduction to seismology, earthquakes, and earth structure. Blackwell Publishing, Oxford
Udias A (1977) Time and magnitude relations for three microaftershock series near Hollister, California. Bull Seismol Soc Am 67(1): 173

Urbancic T, Trifu C, Long J, Young R (1992) Space-time correlations of $b$ values with stress release. Pure Appl Geophys 139(3):449-462

Utsu T (1965) A method for determining the value of $b$ in a formula $\log n=a-b M$ showing the magnitude-frequency relation for earthquakes. Geophys Bull Hokkaido Univ 13:99-103

Utsu T (1971) Aftershocks and earthquake statistics (2): further investigation of aftershocks and other earthquake sequences based on a new classification of earthquake sequences. J Fac Sci Hokkaido Univ. Series 7, Geophysics 3(4):197-266

Wang J (1988) $b$ values of shallow earthquakes in Taiwan. Bull Seismol Soc Am 78(3): 1243

Wech A, Kenneth W, Creager C, Houston H, Vidale J (2010) An earthquake-like magnitude-frequency distribution of slow slip in northern Cascadia. Geophys Res Letters 37:L22310

Wiemer S, Wyss M (1997) Mapping the frequency-magnitude distribution in asperities: an improved technique to calculate recurrence times? J Geophy Res 102(B7):15115-15128

Wiemer S, Benoit J (1996) Mapping the B-value anomaly at $100 \mathrm{~km}$ depth in the Alaska and New Zealand subduction zones. Geophys Res Lett 23(13):1557-1560

Wiemer S, Wyss M (2002) Mapping spatial variability of the frequency-magnitude distribution of earthquakes. Adv Geophys 45:259-302

Wiemer S, McNutt S, Wyss M (1998) Temporal and three-dimensional spatial analyses of the frequency-magnitude distribution near Long Valley Caldera, California. Geophys J Int 134(2):409-421

Wyss M (1973) Towards a physical understanding of the earthquake frequency distribution. Geophys J Roy Astron Soc 31(4):341-359

Wyss M, Bodin P, Habermann R (1990) Seismic quiescence at Parkfield: an independent indication of an imminent earthquake. Nature 345:426-428

Wyss M, Booth D (1997) The IASPEI procedure for the evaluation of earthquake precursors. Geophys J Int 131(3):423-424

Wyss M, Matsumura S (2006) Verification of our previous definition of preferred earthquake nucleation areas in Kanto-Tokai, Japan. Tectonophysics 417(1-2):81-84

Wyss M, Stefansson R (2006) Nucleation points of recent mainshocks in southern Iceland, mapped by $b$-values. Bull Seismol Soc Am 96(2):599

Wyss M, Sammis C, Nadeau R, Wiemer S (2004) Fractal dimension and $b$-value on creeping and locked patches of the San Andreas fault near Parkfield, California. BSSA 94(2):410

Zuniga F, Wyss M (2001) Most-and least-likely locations of large to great earthquakes along the Pacific coast of Mexico estimated from local recurrence times based on $b$-values. Bull Seismol Soc Am 91(6): 1717 